Research Article

\title{
Rub-Impact Detection in Rotor Systems with Pedestal Looseness Using a Nonlinearity Evaluation
}

\author{
Mian Jiang $(\mathbb{D}$, Yingwei Kuang, Jigang Wu $\mathbb{D}$, and Xuejun Li \\ Hunan Provincial Key Laboratory of Health Maintenance for Mechanical Equipment, \\ Hunan University of Science and Technology, Xiangtan 411201, China
}

Correspondence should be addressed to Jigang Wu; jwu@cvm.ac.cn

Received 6 March 2018; Accepted 29 October 2018; Published 27 November 2018

Academic Editor: Juan C. G. Prada

Copyright (c) 2018 Mian Jiang et al. This is an open access article distributed under the Creative Commons Attribution License, which permits unrestricted use, distribution, and reproduction in any medium, provided the original work is properly cited.

\begin{abstract}
In this paper, a nonlinearity evaluation is proposed in order to identify the rub-impact in rotor systems with pedestal looseness. Nonlinear mathematical models have been established for bearing-rotor systems with single pedestal looseness and pedestal looseness coupled with rub-impact. Piecewise linear stiffness and damping are considered regarding the position of pedestal looseness, while radial impact forces are defined using the Colulomb type of frictional relationship during rub-impact. The nonlinearity evaluation is employed to quantify the nonlinearity of the dynamics of bearing-rotor systems, which are calculated at different looseness clearances. The experiments for rotor systems with pure pedestal looseness and pedestal looseness coupled with rub-impact are conducted respectively to collect the vibration signals on different looseness clearances. Two different curves are obtained using the nonlinear fitting method for the values of nonlinearity evaluation. The rub-impact within rotor systems with pedestal looseness can then be identified by comparing the curves that denote the trend of nonlinearity evaluation for the measured vibration responses.
\end{abstract}

\section{Introduction}

Pedestal looseness is a common issue in rotating machinery. The excessive vibration caused by pedestal looseness often results in a secondary phenomenon, rub-impact [1]. Rotorto-stator rub remains one of the primary causes of serious malfunctions that occur in rotating machinery. In recent years, there has been a focus on determining whether rubbing is occurring in a rotor system [2-7]. However, the partial rub and pedestal looseness have the same contact and separation process, and the dynamic characteristics and signatures of the measured vibration signals of a rotor system will appear similar. Thus, distinguishing between partial rub and pedestal looseness by measured signals is challenging [8]. Using signal-based methods alone, it is difficult to identify rub-impact from rotor systems with pedestal looseness in rotating machinery.

There has been extensive research in the past decades regarding the detection of rubbing faults in a rotor system. The methods of detection can be divided into signals-based identification methods [9-12] and model-based identification methods [13-16]. The former uses the measured vibrations to describe the dynamics of the rotor system to detect the possible underlying reason for rubbing. The various signal processing techniques such as FFT, STFT, Hilbert-Huang transform (HHT) [8], ensemble local means decomposition [17], and variational mode decomposition (VMD) [18] are widely used and have been proven to be powerful. To overcome the difficulty in detecting the rubbing location, the model-based identification method is employed to provide quantitative information regarding the faults, including locations and severity. This method combines the dynamic characteristics and the dynamic model of the rotor systems with the signal processing techniques [19-22]. Despite a lot of research focusing on the analysis of the rotor systems with pedestal looseness [23-28], these methods have not been applied to identify the rub-impact in rotor systems with pedestal looseness.

Rotor systems with pedestal looseness can be described by a nonlinear mathematical model containing stiffness and 
damping forces with trilinear forms [28]. Due to the existence of nonlinear bearing forces within the system, a bearing-rotor system with pedestal looseness demonstrates nonlinear dynamic behaviors, with complex and nonstationary vibration characteristics. When rub-impact occurs in rotor systems with pedestal looseness, the nonlinear rubbing forces with a piecewise linear form of stiffness are also considered in the system $[29,30]$. Rotor systems with pedestal looseness coupled with rub-impact will become much more complicated, and its nonlinearity effects on the dynamics of the system will become increasingly more serious. Numerically, the severity of the nonlinearity can be quantified by a nonlinearity evaluation (also called a nonlinearity measure or a nonlinearity test), which represents an approach to systematically quantify the degree of nonlinearity of a dynamical system [31, 32]. Therefore, a nonlinearity evaluation has the capacity to identify the variation of nonlinearity severity on the dynamics of the rotor systems.

In this paper, a nonlinearity evaluation is proposed to identify the rub-impact in rotor systems with pedestal looseness. Nonlinear mathematical models are established for rotor systems with single pedestal looseness as well as pedestal looseness coupled with rub-impact. The elastic force and the rubbing force are considered in regards to the position of pedestal looseness and rubbing. Then, the severity of the nonlinearity of the rotor systems is quantified using a nonlinearity evaluation. The definition of nonlinearity measure is introduced and a special case is used to quantify the nonlinearity of dynamics. The dynamics of rotor systems with pedestal looseness coupled with rub-impact is analyzed by integration using the adaptive fourth-order Runge-Kutta method for the mathematical models. Different looseness clearances are used in order to calculate the degree of nonlinearity of the dynamics in rotor systems. The experiments are conducted to verify the effectiveness of the proposed method. Two kinds of experiments are used to collect the vibration responses on the different setting looseness clearances. Two curves are obtained by nonlinear fitting method for the values of nonlinearity measures on different looseness clearances. Then, rub-impact can be identified from the rotor systems with pedestal looseness by comparing the curves that denote the trend of the nonlinearity evaluation.

\section{Modelling for Rotor Systems with Pedestal Looseness Coupled with Run-Impact}

2.1. Model for Rotor Systems with Pedestal Looseness. A simple rotor system with two identical oil film bearings at both sides is shown in Figure 1. The shaft sections in the system between the disk and the bearings are considered to be elastic and massless. The equivalent lumped mass in the position of the disk is $m_{2}$, which is $m_{1}$ in the position of the bearings. It is assumed that the left support has the single pedestal looseness, the maximum static gap of the looseness is $\delta$, and the lumped mass of the pedestal involving the looseness is $m_{3} . c_{1}, c_{2}$ are the equivalent damping coefficients in the positions of bearing and disk, respectively, while $k$ is the stiffness coefficient of the shaft. The foundation, or the joint to

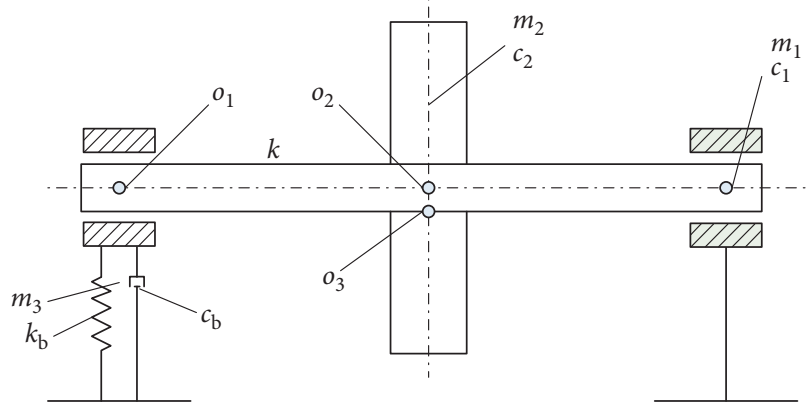

Figure 1: Bearing-rotor system with single pedestal looseness.

the pedestal, is equivalent to a spring-damping system with the damping coefficients $k_{\mathrm{b}}$ and $c_{\mathrm{b}}$.

It is assumed that the horizontal and vertical displacements in the right-bearing position are $x_{1}, y_{1}$, in the disk position $x_{2}, y_{2}$, in the left-bearing position $x_{3}, y_{3}$. The small movement of the left pedestal in the horizontal direction is considered to be negligible, and its displacement in the vertical direction is $y_{4}$. The differential equations for the bearing-rotor system with single pedestal looseness can then be written as follows:

$N_{\mathrm{p}}(\omega):\left\{\begin{array}{l}m_{1} \ddot{x}_{1}+c_{1} \dot{x}_{1}+k\left(x_{1}-x_{2}\right)=F_{x}\left(x_{1}, y_{1}, \dot{x}_{1}, \dot{y}_{1}\right), \\ m_{1} \ddot{y}_{1}+c_{1} \dot{y}_{1}+k\left(y_{1}-y_{2}\right)=F_{y}\left(x_{1}, y_{1}, \dot{x}_{1}, \dot{y}_{1}\right)-m_{1} g, \\ m_{2} \ddot{x}_{2}+c_{2} \dot{x}_{2}+k\left(x_{2}-x_{1}\right)+k\left(x_{2}-x_{3}\right)=m_{2} e_{\mathrm{b}} \omega^{2} \cos (\omega t), \\ m_{2} \ddot{y}_{2}+c_{2} \dot{y}_{2}+k\left(y_{2}-y_{1}\right)+k\left(y_{2}-y_{3}-y_{4}\right)=m_{2} e_{\mathrm{b}} \omega^{2} \sin (\omega t)-m_{2} g, \\ m_{1} \ddot{x}_{3}+c_{1} \dot{x}_{3}+k\left(x_{3}-x_{2}\right)=F_{x}\left(x_{3}, y_{3}-y_{4}, \dot{x}_{3}, \dot{y}_{3}-\dot{y}_{4}\right), \\ m_{1} \ddot{y}_{3}+c_{1} \dot{y}_{3}+k\left(y_{3}+y_{4}-y_{2}\right)=F_{y}\left(x_{3}, y_{3}-y_{4}, \dot{x}_{3}, \dot{y}_{3}-\dot{y}_{4}\right)-m_{1} g, \\ m_{3} \ddot{y}_{4}+c_{b} \dot{y}_{4}+\left(k y_{4}+k_{b} y_{4}\right)=-F_{y}\left(x_{3}, y_{3}-y_{4}, \dot{x}_{3}, \dot{y}_{3}-\dot{y}_{4}\right)-m_{3} g,\end{array}\right.$

where $e_{\mathrm{b}}$ is the unbalance, $\omega$ is the rotating speed.

When the pedestal looseness occurs, the equivalent stiffness and the damping coefficients of the foundation, or the joint to the pedestal, can be expressed using the following piecewise linear structure [28]:

$$
\begin{aligned}
& k_{\mathrm{b}}= \begin{cases}k_{\mathrm{b} 1}, & y_{4}<0, \\
k_{\mathrm{b} 2}, & 0 \leq y_{4} \leq \delta, \\
k_{\mathrm{b} 3}, & y_{4}>\delta,\end{cases} \\
& c_{\mathrm{b}}= \begin{cases}c_{\mathrm{b} 1}, & y_{4}<0, \\
c_{\mathrm{b} 2}, & 0 \leq y_{4} \leq \delta, \\
c_{\mathrm{b} 3}, & y_{4}>\delta,\end{cases}
\end{aligned}
$$

where stiffness and damping actions are considered in three parts.

If the bearings are oil film bearings, $F_{x}\left(x_{1}, y_{1}, \dot{x}_{1}, \dot{y}_{1}\right)$, $F_{y}\left(x_{1}, y_{1}, \dot{x}_{1}, \dot{y}_{1}\right)$ in equation (1) denote the force components of the oil film in the right bearing in the horizontal and vertical directions, while $F_{x}\left(x_{3}, y_{3}-y_{4}, \dot{x}_{3}, \dot{y}_{3}-\dot{y}_{4}\right)$, $F_{y}\left(x_{3}, y_{3}-y_{4}, \dot{x}_{3}, \dot{y}_{3}-\dot{y}_{4}\right)$ are that of the left bearing. The nonlinear forces from the journal bearing are obtained under the short bearing theory $[33,34]$. For the sake of convenience, $F_{x}, F_{y}$ are used to denote the components of the oil film force for two bearings in the horizontal and vertical directions, which is calculated using 


$$
\begin{aligned}
& F_{x}=s f_{x}, \\
& F_{y}=s f_{y},
\end{aligned}
$$

where the adjustment factor $s=\mu \omega R L[R / c]^{2}[L /(2 R)]^{2}, \omega$ is the rotating speed, $R$ is the radius of bearing, $L$ is the length of bearing, $c$ is the bearing clearance, and $\mu$ is the oil viscosity. The force components $f_{x}, f_{y}$ in the $x$ and $y$ directions can be obtained using the following equations:

$$
\begin{aligned}
{\left[\begin{array}{l}
f_{x} \\
f_{y}
\end{array}\right]=} & \frac{\sqrt{(x-2 \dot{y})^{2}+(y+2 \dot{x})^{2}}}{1-x^{2}-y^{2}} \\
& \times\left[\begin{array}{l}
3 x V-\sin \beta E-2 \cos \beta S \\
3 y V+\cos \beta E-2 \sin \beta S
\end{array}\right],
\end{aligned}
$$

where $V, E, S, \beta$ can be represented as

$$
\begin{aligned}
V(x, y, \beta)= & \frac{\sqrt{(x-2 \dot{y})^{2}+(y+2 \dot{x})^{2}}}{1-x^{2}-y^{2}}, \\
S(x, y, \beta)= & \frac{x \cos \beta+y \sin \beta}{1-(x \cos \beta+y \sin \beta)^{2}}, \\
E(x, y, \beta)= & \frac{2}{\sqrt{1-x^{2}-y^{2}}}\left(\frac{\pi}{2}+\arctan \left(\frac{y \cos \beta-x \sin \beta}{\sqrt{1-x^{2}-y^{2}}}\right)\right), \\
\beta(x, y)= & \arctan \frac{y+2 \dot{x}}{x-2 \dot{y}}-\frac{\pi}{2} \operatorname{sign}\left(\frac{y+2 \dot{x}}{x-2 \dot{y}}\right) \\
& -\frac{\pi}{2} \operatorname{sign}(y+2 \dot{x}) .
\end{aligned}
$$

If there is no pedestal looseness existed in the rotor systems, the dynamics of rotor systems can be described by the following differential equations:

$$
N_{0}(\omega):\left\{\begin{array}{l}
m_{1} \ddot{x}_{1}+c_{1} \dot{x}_{1}+k\left(x_{1}-x_{2}\right)=F_{x}\left(x_{1}, y_{1}, \dot{x}_{1}, \dot{y}_{1}\right), \\
m_{1} \ddot{y}_{1}+c_{1} \dot{y}_{1}+k\left(y_{1}-y_{2}\right)=F_{y}\left(x_{1}, y_{1}, \dot{x}_{1}, \dot{y}_{1}\right)-m_{1} g, \\
m_{2} \ddot{x}_{2}+c_{2} \dot{x}_{2}+k\left(x_{2}-x_{1}\right)+k\left(x_{2}-x_{3}\right)=m_{2} e_{\mathrm{b}} \omega^{2} \cos (\omega t), \\
m_{2} \ddot{y}_{2}+c_{2} \dot{y}_{2}+k\left(y_{2}-y_{1}\right)+k\left(y_{2}-y_{3}\right)=m_{2} e_{\mathrm{b}} \omega^{2} \sin (\omega t)-m_{2} g, \\
m_{1} \ddot{x}_{3}+c_{1} \dot{x}_{3}+k\left(x_{3}-x_{2}\right)=F_{x}\left(x_{3}, y_{3}, \dot{x}_{3}, \dot{y}_{3}\right), \\
m_{1} \ddot{y}_{3}+c_{1} \dot{y}_{3}+k\left(y_{3}-y_{2}\right)=F_{y}\left(x_{3}, y_{3}, \dot{x}_{3}, \dot{y}_{3}\right)-m_{1} g,
\end{array}\right.
$$

where $F_{x}\left(x_{1}, y_{1}, \dot{x}_{1}, \dot{y}_{1}\right), F_{y}\left(x_{1}, y_{1}, \dot{x}_{1}, \dot{y}_{1}\right)$ denote the force components of the oil film in the right bearing in the horizontal and vertical directions, while $F_{x}\left(x_{3}, y_{3}, \dot{x}_{3}, \dot{y}_{3}\right)$, $F_{y}\left(x_{3}, y_{3}, \dot{x}_{3}, \dot{y}_{3}\right)$ are that of the left bearing.

2.2. Model for Rotor Systems with Pedestal Looseness Coupled with Rub-Impact. If rub-impact occurs in the rotor system (1) with single pedestal looseness, the previously described model with identical oil film bearings with rotor-to-stator rub is shown in Figure 2.

Partial rub between the rotor and the stator is taken into consideration in the rotor-bearing system with pedestal

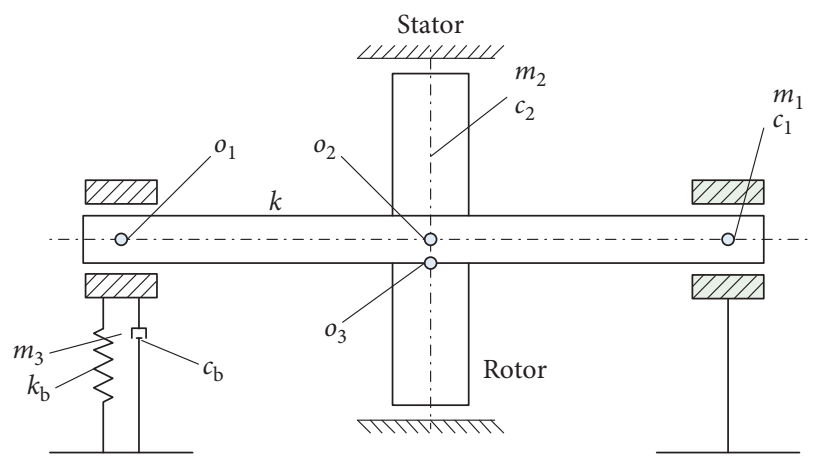

Figure 2: Bearing-rotor system with pedestal looseness coupled with rub-impact.

looseness in this paper. An initial clearance of $\delta_{1}$ between the rotor and the stator is assumed for rub-impact. When comparing with one complete rotation period, the duration time of the rub-impact is very short. An elastic impact model is then used, neglecting the thermal effect of friction. Additionally, the Colulomb type of frictional relationship is assumed in the analysis of the dynamics.

When rub-impact occurs, as shown in Figure 3, $(x, y)$ denotes the coordinates of the rotor center, $\varphi$ is the angular displacement, and $\omega$ is the rotating speed. The radial impact force $G_{\mathrm{n}}$ and the tangential rub force $G_{\mathrm{r}}$ can thus be expressed as [6]

$$
\left\{\begin{array}{l}
G_{\mathrm{n}}= \begin{cases}0, & \left(R_{\mathrm{r}}<\delta_{1}\right), \\
\left(R_{\mathrm{r}}-\delta_{1}\right) k_{\mathrm{c}}, & \left(R_{\mathrm{r}} \geq \delta_{1}\right),\end{cases} \\
G_{\mathrm{r}}=f G_{\mathrm{n}},
\end{array}\right.
$$

where $f$ is the friction coefficient between the rotor and the stator, $k_{\mathrm{c}}$ is the radial stiffness of the stator, and $R_{\mathrm{r}}=\sqrt{x^{2}+y^{2}}$ is the radial displacement of the rotor. These two forces can be written in the $x-y$ coordinate as follows:

$$
\begin{aligned}
& G_{x}=-G_{\mathrm{n}} \cos \varphi+G_{\mathrm{r}} \sin \varphi, \\
& G_{y}=-G_{\mathrm{n}} \sin \varphi+G_{\mathrm{r}} \cos \varphi,
\end{aligned}
$$

which can be rewritten as

$$
\left\{\begin{array}{l}
G_{x} \\
G_{y}
\end{array}\right\}=\left[\begin{array}{ll}
-\cos \varphi & \sin \varphi \\
-\sin \varphi & \cos \varphi
\end{array}\right]\left[\begin{array}{l}
G_{\mathrm{n}} \\
G_{\mathrm{r}}
\end{array}\right] .
$$

Because $\sin \varphi=y / R, \cos \varphi=x / R$, the forces $G_{x}, G_{y}$ can be expressed as follows:

$$
\begin{aligned}
& \left\{\begin{array}{l}
G_{x}=\frac{\left(R_{\mathrm{r}}-\delta_{1}\right) k_{\mathrm{c}}}{R_{\mathrm{r}}}(x-f y), \\
G_{y}=\frac{\left(R_{\mathrm{r}}-\delta_{1}\right) k_{\mathrm{c}}}{R_{\mathrm{r}}}(y+f x),
\end{array} \quad\left(R_{r} \geq \delta_{1}\right),\right. \\
& G_{x}=G_{y}=0, \quad\left(R_{r}<\delta_{1}\right) .
\end{aligned}
$$

When comparing to the differential equation (1) for the rotor system with single pedestal looseness, rub forces are taken into consideration for this situation. Then, the differential equation for rotor systems with pedestal looseness coupled with rub-impact can be obtained as follows: 


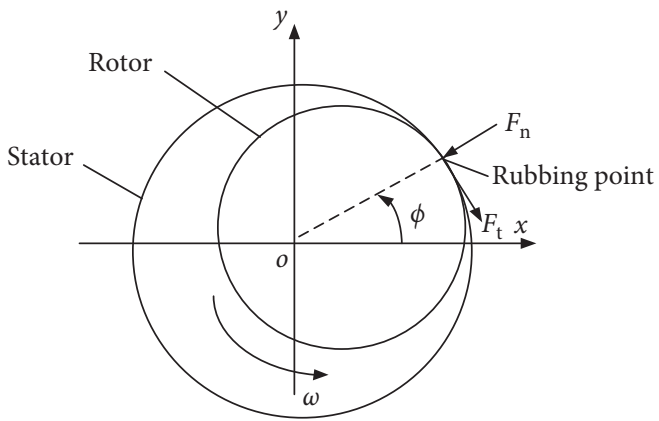

Figure 3: Rub-impact.

$$
N_{\mathrm{r}}(\omega):\left\{\begin{array}{l}
m_{1} \ddot{x}_{1}+c_{1} \dot{x}_{1}+k\left(x_{1}-x_{2}\right)=F_{x}\left(x_{1}, y_{1}, \dot{x}_{1}, \dot{y}_{1}\right), \\
m_{1} \ddot{y}_{1}+c_{1} \dot{y}_{1}+k\left(y_{1}-y_{2}\right)=F_{y}\left(x_{1}, y_{1}, \dot{x}_{1}, \dot{y}_{1}\right)-m_{1} g, \\
m_{2} \ddot{x}_{2}+c_{2} \dot{x}_{2}+k\left(x_{2}-x_{1}\right)+k\left(x_{2}-x_{3}\right)=G_{x}\left(x_{2}, y_{2}\right)+m_{2} e \omega^{2} \cos (\omega t), \\
m_{2} \ddot{y}_{2}+c_{2} \dot{y}_{2}+k\left(y_{2}-y_{1}\right)+k\left(y_{2}-y_{3}-y_{4}\right)=G_{y}\left(x_{2}, y_{2}\right)+m_{2} e \omega^{2} \sin (\omega t)-m_{2} g, \\
m_{1} \ddot{x}_{3}+c_{1} \dot{x}_{3}+k\left(x_{3}-x_{2}\right)=F_{x}\left(x_{3}, y_{3}-y_{4}, \dot{x}_{3}, \dot{y}_{3}-\dot{y}_{4}\right), \\
m_{1} \ddot{y}_{3}+c_{1} \dot{y}_{3}+k\left(y_{3}+y_{4}-y_{2}\right)=F_{y}\left(x_{3}, y_{3}-y_{4}, \dot{x}_{3}, \dot{y}_{3}-\dot{y}_{4}\right)-m_{1} g, \\
m_{3} \ddot{y}_{4}+c_{b} \dot{y}_{4}+\left(k y_{4}+k_{b} y_{4}\right)=-F_{y}\left(x_{3}, y_{3}-y_{4}, \dot{x}_{3}, \dot{y}_{3}-\dot{y}_{4}\right)-m_{3} g .
\end{array}\right.
$$

Because of the partial rub between rotor and stator, the radial impact force and the tangential rub force are considered in the equation (11). Comparing with the dynamical model (1), this will give more complicate nonlinear dynamics than the rotor system with pure pedestal looseness. It can be concluded that the nonlinearity effects on the dynamics of the rotor system will become more serious, which is verified by the finite element analysis [30]. If the partial rub occurs in rotor systems with pure pedestal looseness, the severity of nonlinearity in rotor systems will increase significantly. Mathematically, this variation can be identified by using a nonlinearity measure to quantify the nonlinearity degree of the dynamics.

\section{Nonlinearity Evaluation for the Dynamics of Rotor Systems}

3.1. Definition of Nonlinearity Evaluation. The evaluation of the nonlinearity represents an approach to systematically quantify the degree of nonlinearity for dynamical systems $[31,32]$, which is also referred to as the nonlinearity measure or nonlinearity test. The fundamental idea underlying the evaluation of nonlinearity is to compare the dynamic behaviors of the nonlinear systems with a certain linear system in an appropriate setup. The most common setup for nonlinearity measures is depicted in Figure 4 [32].

Assuming that a nonlinear stable dynamical system $N$ has the transfer operator $N: u \longmapsto y=N(u)$, this is compared to a linear model that has the linear transfer operator $G: u \longmapsto \bar{y}=G(u)$, which is used to approximate the behaviors of the system $N . u, y, \bar{y}$ represent the input and output trajectories of the systems $N$ and $G$, respectively. Without a loss of generality, it is assumed that $N[0]=0$. The error is defined as the difference between the output $y$ of the nonlinear system $N$ and the output $\bar{y}$ of the linear system $G$. This error measurement provides information regarding how well the dynamical behaviors of a nonlinear system resemble that of a certain linear model. To evaluate the nonlinearity of the dynamics, the following definition is employed to compute the nonlinearity degree, which has been proposed by T. Schweickhardt and F. Allgower [31]:

$$
\phi_{N}^{u}=\inf _{G \in \mathscr{G}} \sup _{u \in U} \frac{\|N(u)-G(u)\|}{\|N(u)\|},
$$

where $N(u)$ is the output of the nonlinear system $N, G(u)$ is the output of the linear model $G$, and $\phi_{N}^{u}$ denotes the value of the nonlinearity quantification using the input $u$. It is evident that the nonlinearity evaluation depends on the linear system $G$ and the set of considered inputs $U$. The set $U$ typically describes the region of operation in which the nonlinearity of the system $N$ is to be assessed. In this paper, the constant rotational speed $\omega$ is selected as the input $u$ for systems $N$ and $G$. Then, the following definition is used to quantify the nonlinearity of rotor-bearing systems:

$$
\phi_{N}^{\omega}=\inf _{G \in \mathscr{G}} \frac{\|N(\omega)-G(\omega)\|}{\|N(\omega)\|} .
$$

The most important step in nonlinearity evaluation is to identify a proper linear model to compare its dynamic behaviors with that of the original nonlinear model. Computation of $\phi_{N}^{\omega}$ in equation (13) can be extremely complicated, because the minimization must be performed over all linear operators $G$ in the set $\mathscr{G}$. Due to the computation requirement for engineering applications, it is appropriate to use a simple definition of nonlinearity quantification. In some situations $[35,36]$, Taylor expansions are used to obtain the linear approximations on the vicinity of the equilibrium position. 


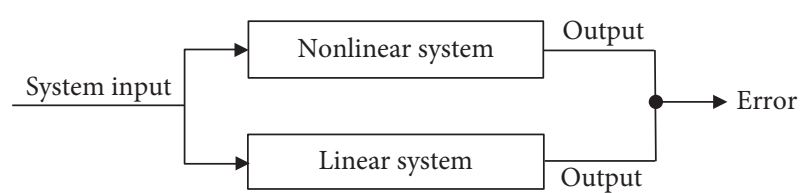

FIGURE 4: Setup for the comparison of a nonlinear system with a linear system.

Linearizing the nonlinear terms on the static equilibrium position allows for a linear system $L(\omega)$ to be derived to calculate the dynamical differences between the outputs. The details of the procedure for Taylor expansions of nonlinear terms are shown in Appendix A. As a special case of linear approximated system, then

$$
\phi_{N}^{\omega}=\inf _{G \in \mathscr{G}} \frac{\|N(\omega)-G(\omega)\|}{\|N(\omega)\|} \leq \frac{\|N(\omega)-L(\omega)\|}{\|N(\omega)\|} .
$$

The equation (14) is a special case of the definition of nonlinearity measure, which is used to assess the pedestal looseness of rotor systems in References [35, 36]. However, different linear model will influence on the nonlinearity quantification on a real rotor system by using the directly measured data. To improve the applicability of the method, the model $N_{0}(\omega)$ in equation (6) for rotor system with no pedestal looseness is introduced in equation (14) to obtain an upper bound to measure the severity of nonlinearity for dynamics:

$$
\begin{aligned}
\frac{\|N(\omega)-L(\omega)\|}{\|N(\omega)\|}= & \frac{\left\|N(\omega)-N_{0}(\omega)+N_{0}(\omega)-L(\omega)\right\|}{\|N(\omega)\|} \\
& \leq \frac{\left\|N(\omega)-N_{0}(\omega)\right\|+\left\|N_{0}(\omega)-L(\omega)\right\|}{\|N(\omega)\|}, \\
\phi_{N}^{\omega} \leq & \frac{\left\|N(\omega)-N_{0}(\omega)\right\|}{\|N(\omega)\|}+d,
\end{aligned}
$$

where $d=\left\|N_{0}(\omega)-L(\omega)\right\| /\|N(\omega)\|$, and it can be computed according to the model (6) and its linear approximation by Taylor expansion. Then, the following definition of nonlinearity measure is used to quantify the nonlinearity of rotor systems (11):

$$
\phi_{\mathrm{r}}=\frac{\left\|N_{\mathrm{r}}(\omega)-N_{0}(\omega)\right\|}{\|N(\omega)\|}+d
$$

Similarly, the following definition (17) is used to quantify the nonlinearity of rotor systems (1).

$$
\phi_{\mathrm{p}}=\frac{\left\|N_{\mathrm{p}}(\omega)-N_{0}(\omega)\right\|}{\|N(\omega)\|}+d .
$$

In the above equations, $\|(\cdot)\|$ is the norm, with the following definition:

$$
\|x(\cdot)\|=\sqrt{\int_{0}^{\infty}|x(t)|^{2} d t},
$$

where $x(t)$ denotes the nonlinear vibration signals that describe the dynamical outputs of the dynamic systems. The energy contained in the signal $x(t)$ over the infinite time interval $t \geq 0$ is described by equation (18). However, in principle, any norm can be used for the following considerations. The evaluation of norm in equation (18) requires the following numerical approximation:

$$
\|x(\cdot)\| \approx \sqrt{\int_{0}^{T_{\max }}|x(t)|^{2} d t}=\sqrt{\Delta t \sum_{i=1}^{t_{\text {nim }}}\left|x\left(t_{i}\right)\right|^{2}},
$$

where $\left\{t_{i}, i=1,2, \ldots, t_{\text {nim }}\right\}$ are equally spaced mesh points in the interval $\left[0, T_{\max }\right]$, and $\Delta t$ is the average sampling time. The maximum integration time $T_{\max }$ can be considered as a characteristic time of the system, based on a certain degree of physical knowledge of rotor systems.

The result of the nonlinearity evaluation (16) and (17) will satisfy $\phi_{\mathrm{p}}, \phi_{\mathrm{r}} \geq d$. Discussing the nonlinear equations of motions in an analytical way is quite challenging; therefore, numerical methods have to be resorted for the calculations of the nonlinearity evaluation. The parameter values used for the nonlinearity measure and simulations are given in Table 1 of Appendix B, while the values of the parameters for oil film bearings and rub-impact used in the numerical examples are given in Tables 2 and 3, respectively. Some parameters used in the simulations are chosen as the same as Tables 1 and 2 in References $[35,36]$. The adaptive fourth-order Runge-Kutta method is used to integrate the dynamic systems, while a smaller marching step is chosen to ensure a stable solution and to avoid the numerical divergence at the point where the damping and stiffness parameters are discontinuous. To maintain the accuracy of integrations, nondimensionalization is used to transform the systems into new ones, which can be implemented by using

$$
\begin{aligned}
& X^{\prime}=\frac{X}{c}, \\
& \dot{X}^{\prime}=\frac{\dot{X}}{(c \omega)}, \\
& \ddot{X}^{\prime}=\frac{\ddot{X}}{\left(c \omega^{2}\right)},
\end{aligned}
$$

where $X=\left[x_{1}, y_{1}, x_{2}, y_{2}, x_{3}, y_{3}, y_{4}\right]$ or $X=\left[x_{1}, y_{1}\right.$, $\left.x_{2}, y_{2}, x_{3}, y_{3}\right], c$ is the average thickness of oil film, and $\omega$ is the rotating speed of the bearing-rotor systems.

\subsection{Nonlinearity Evaluations for the Dynamics of Rotor} Systems. A nonlinear vibrating system with seven degrees of freedom and piecewise linear stiffness and damping is represented by equation (11). In comparison to equation (1), the difference is that there are two rub forces in the position of the disk. The force components of the oil film and the rubimpact forces have nonlinear characteristics. To calculate the value of $d$ in equation (11), Taylor expansion is used to 
TABLE 1: Values of the simulation parameters.

\begin{tabular}{lccc}
\hline Parameter & Value & Parameter & Value \\
\hline$e$ & $0.5 \times 10^{-4} \mathrm{~m}$ & $m_{1}$ & $32.1 \mathrm{~kg}$ \\
$k$ & $2.5 \times 10^{7} \mathrm{~N} / \mathrm{m}$ & $m_{2}$ & $4 \mathrm{~kg}$ \\
$k_{b 1}$ & $7.5 \times 10^{9} \mathrm{~N} / \mathrm{m}$ & $m_{3}$ & $10 \mathrm{~kg}$ \\
$k_{b 2}$ & 0 & $\omega$ & $2100 \mathrm{rpm}$ \\
$k_{b 3}$ & $7.5 \times 10^{7} \mathrm{~N} / \mathrm{m}$ & $c_{b 1}$ & $350 \mathrm{~N} \cdot \mathrm{s} / \mathrm{m}$ \\
$c_{1}$ & $1050 \mathrm{~N} \cdot \mathrm{s} / \mathrm{m}$ & $c_{b 2}$ & $100 \mathrm{~N} \cdot \mathrm{s} / \mathrm{m}$ \\
$c_{2}$ & $2100 \mathrm{~N} \cdot \mathrm{s} / \mathrm{m}$ & $c_{b 3}$ & $500 \mathrm{~N} \cdot \mathrm{s} / \mathrm{m}$ \\
\hline
\end{tabular}

TABLE 2: Values of the parameters for oil film bearing.

\begin{tabular}{lccc}
\hline Parameter & Value & Parameter & Value \\
\hline$\mu$ & $0.018 \mathrm{pa} \cdot \mathrm{s}$ & $L$ & $0.012 \mathrm{~m}$ \\
$R$ & $0.025 \mathrm{~m}$ & $c$ & $0.00011 \mathrm{~m}$ \\
\hline
\end{tabular}

TABLE 3: Values of the parameters for rub-impact.

\begin{tabular}{lc}
\hline Parameter & Value \\
\hline$f$ & 0.1 \\
$k_{\mathrm{c}}$ & $3.5 \times 10^{7} \mathrm{~N} / \mathrm{m}$ \\
$\delta_{1}$ & $1.6 \times 10^{-4} \mathrm{~m}$ \\
\hline
\end{tabular}

linearize these nonlinear terms of equation (6) on the static equilibrium position, and a linear model (21) can be developed as follows:

$$
L(\omega):\left\{\begin{array}{l}
m_{1} \ddot{x}_{1}+c_{1} \dot{x}_{1}+k\left(x_{1}-x_{2}\right)=\widetilde{F}_{x}\left(x_{1}, y_{1}, \dot{x}_{1}, \dot{y}_{1}\right), \\
m_{1} \ddot{y}_{1}+c_{1} \dot{y}_{1}+k\left(y_{1}-y_{2}\right)=\widetilde{F}_{y}\left(x_{1}, y_{1}, \dot{x}_{1}, \dot{y}_{1}\right)-m_{1} g, \\
m_{2} \ddot{x}_{2}+c_{2} \dot{x}_{2}+k\left(x_{2}-x_{1}\right)+k\left(x_{2}-x_{3}\right)=m_{2} e_{\mathrm{b}} \omega^{2} \cos (\omega t), \\
m_{2} \ddot{y}_{2}+c_{2} \dot{y}_{2}+k\left(y_{2}-y_{1}\right)+k\left(y_{2}-y_{3}\right)=m_{2} e_{\mathrm{b}} \omega^{2} \sin (\omega t)-m_{2} g, \\
m_{1} \ddot{x}_{3}+c_{1} \dot{x}_{3}+k\left(x_{3}-x_{2}\right)=\widetilde{F}_{x}\left(x_{3}, y_{3}, \dot{x}_{3}, \dot{y}_{3}\right), \\
m_{1} \ddot{y}_{3}+c_{1} \dot{y}_{3}+k\left(y_{3}-y_{2}\right)=\widetilde{F}_{y}\left(x_{3}, y_{3}, \dot{x}_{3}, \dot{y}_{3}\right)-m_{1} g .
\end{array}\right.
$$

$\widetilde{F}_{\underline{x}}\left(x_{1}, y_{1}, \dot{x}_{1}, \dot{y}_{1}\right), \widetilde{F}_{y}\left(x_{1}, y_{1}, \dot{x}_{1}, \dot{y}_{1}\right), \widetilde{F}_{x}\left(x_{3}, y_{3} \dot{x}_{3}, \dot{y}_{3}\right)$, and $\widetilde{F}_{y}\left(x_{3}, y_{3}, \dot{x}_{3}, \dot{y}_{3}\right)$ denote the linear approximations of the oil firm forces of bearings. The calculations for the procedure are given in (A.1) and (A.2) of Appendix A. The values for the parameters used in the nonlinearity measure and the simulations for equations (6), (11), and (21) are given in Appendix B. In order to maintain the accuracy of integration by fourth-order Runge-Kutta method, nondimensionalization is used to transform these systems to new systems using equation (20). Looseness clearances of the pedestal is used as a control parameter in order to perform a detailed investigation on the nonlinear dynamics of the bearing-rotor system, which uses the values 0 to $0.0035 \mathrm{~m}$ for simulations. The vibration amplitudes at the positions of pedestal looseness and disk are collected for investigations; the amplitude spectrums in the frequency domain are also given for analysis purposes.

In the process of nonlinearity evaluation for pedestal looseness coupled with rub-impact, the practical process of generation for rub-impact in the rotor system is simulated. A critical point of looseness clearance is chosen for the generation of rub-impact, and this process is divided into two stages. When the looseness clearance in the pedestal is smaller than the critical point, only single pedestal looseness without rub-impact occurs in the rotor system. Otherwise, the rotor system will have pedestal looseness coupled with rub-impact. Assuming that the critical point of looseness clearance is set to be $0.0002 \mathrm{~m}$, rubbing between the rotor and the stator starts to occur in the rotor system. When the looseness clearance is smaller than $0.0002 \mathrm{~m}$, the equations for rotor systems with single pedestal looseness are used to investigate the dynamic behaviors and for the nonlinearity evaluation. The vibration amplitudes and its spectrums for a bearing-rotor system at the positions of pedestal and disk with a looseness clearance of $0.00002 \mathrm{~m}$ are shown in Figures 5 and 6 , while the orbit at the position of pedestal looseness is shown in Figure 7.

When the looseness clearance is greater than $0.0002 \mathrm{~m}$, the rotor system will have a pedestal looseness coupled with rub-impact. The vibration amplitudes and its spectrums for a bearing-rotor system at the positions of pedestal and disk with a looseness clearance of $0.0002 \mathrm{~m}$ are shown in Figures 8 and 9, respectively, while the orbit at the positions of pedestal looseness is shown in Figure 10. The vibration amplitudes and its spectrums for a bearing-rotor system at the positions of pedestal and disk with a looseness clearance of $0.002 \mathrm{~m}$ are shown in Figures 11 and 12, respectively, while the orbit at the positions of pedestal looseness is shown in Figure 13.

It can be seen in Figures 8 and 11 that the vibration amplitudes will decrease with a reduction in looseness clearances; the responses exhibit more harmonic components with a decreasing in looseness clearances. The vibration amplitudes and the orbits of a rotor system exhibit increasingly nonlinear dynamics with an increase in looseness clearances. The match of looseness clearances and the nonlinearity evaluation is shown in Figure 14, where dot $\left({ }^{*}\right)$ denotes the results of nonlinearity quantification at a given looseness clearance. A nonlinear fitting method with exponential functions, using the same time interval, is used to obtain the trend for the nonlinearity evaluation with the increasing looseness clearances. It can also be found that the values of nonlinearity measure in Figure 14 are larger than $d$, which is calculated according the model of the rotor system with no pedestal looseness.

\section{Experiments and Verifications}

In this section, experiments are conducted to collect the vibration signals of a rotor system for nonlinearity evaluation and demonstrate the effect of the proposed method. The motions of the rotor system are described by the analytical model (1), which the values of the parameters for simulations are given in Tables 1-3 of Appendix B. Some parameters used in simulations are kept the same within experiments, while the others are obtained from the references (using the similar experiment setup to collect the vibration signals). The analytical models show the increasingly nonlinear dynamics of the rotor system with an increase in looseness clearances, which can guide the implementation of experiments and data analysis. 

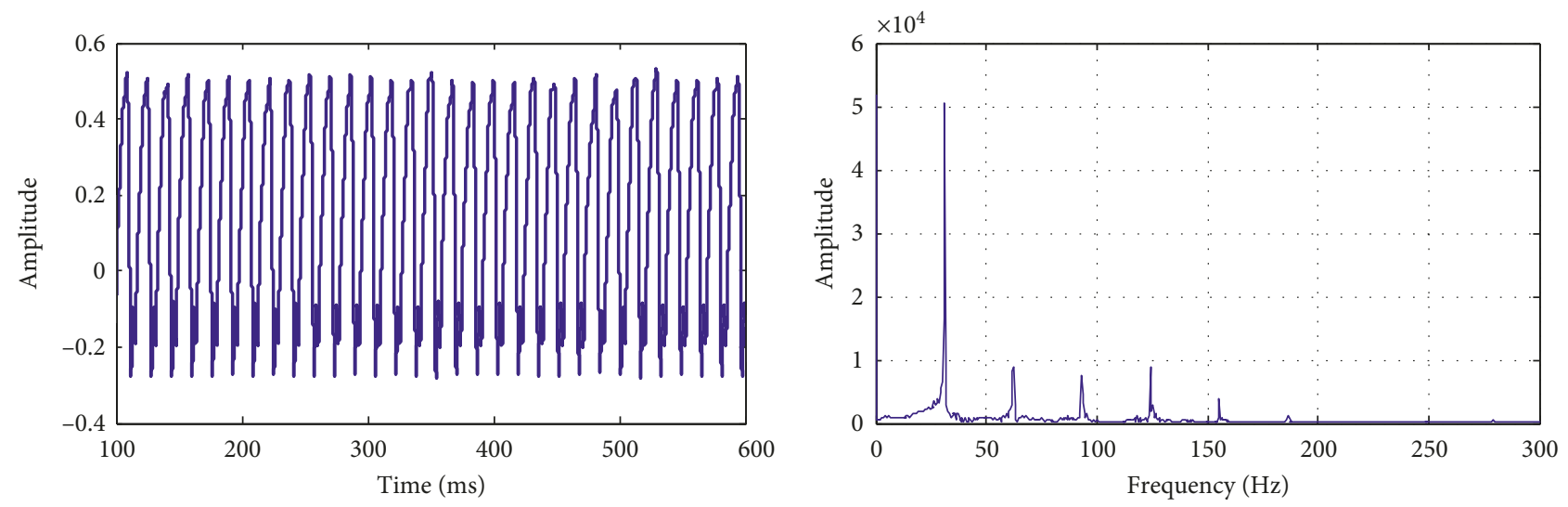

FIGURE 5: Vertical vibration amplitude signals and its frequency diagram on left bearing.
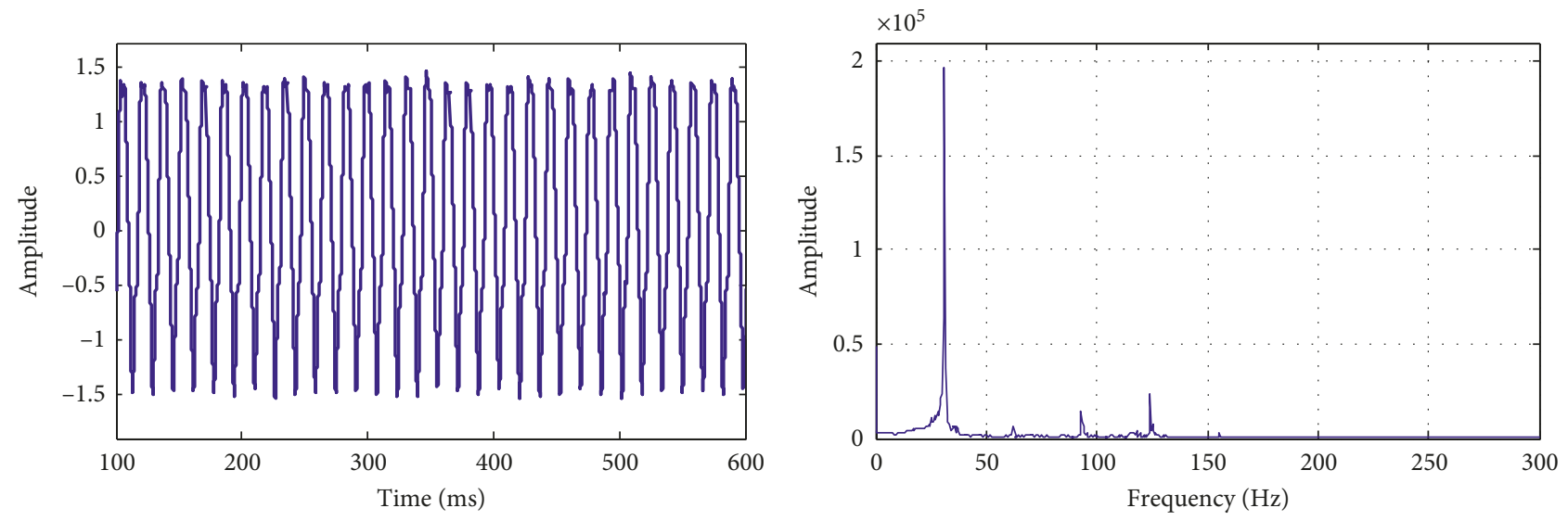

Figure 6: Vertical vibration amplitude signals and its frequency diagram on the disk.

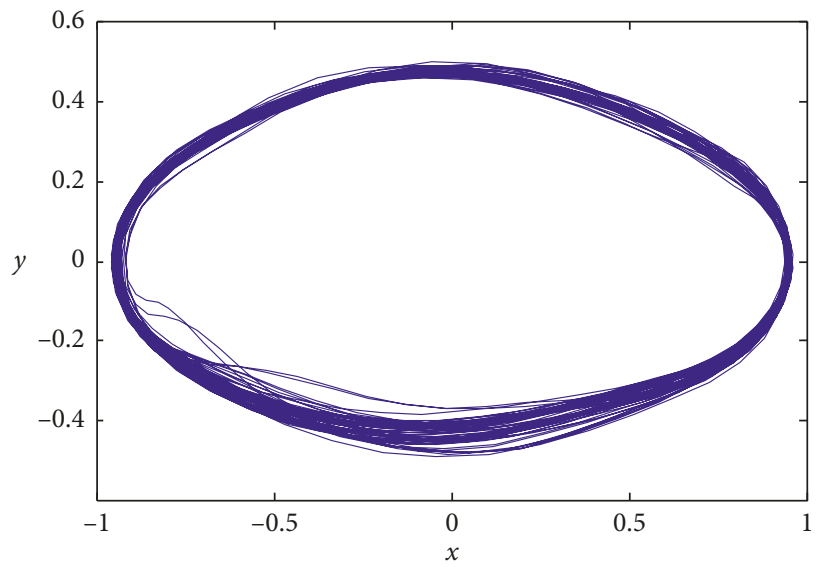

FIGURE 7: Orbits at the position of pedestal looseness (looseness clearance $=0.00002 \mathrm{~m}$ ).

Due to the restrictions of experimental conditions, less number of looseness clearances can be used to conduct the process of signals collection, dynamics analysis, and nonlinearity evaluation. It is shown that the trend of nonlinearity evaluation obtained from experiments remains to be largely consistent with that from simulations. Two kinds of experiments are conducted for the rotor system with pure pedestal looseness and with pedestal looseness coupled with rub-impact. The trend curves with the increasing looseness clearances show that the rubimpact will have important influences on the nonlinearity degrees of the dynamics, which can be used to identify the existence of rub-impact in rotor systems with pure pedestal looseness. 

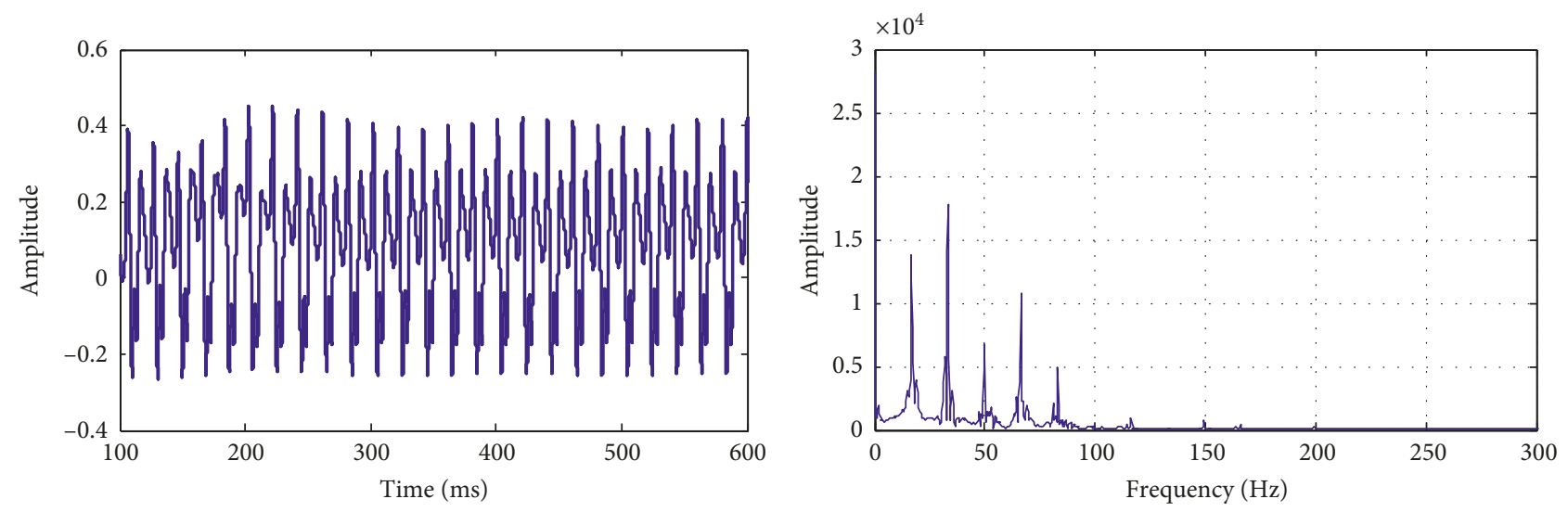

FIGURE 8: Vertical vibration amplitude signals and its frequency diagram on left bearing.
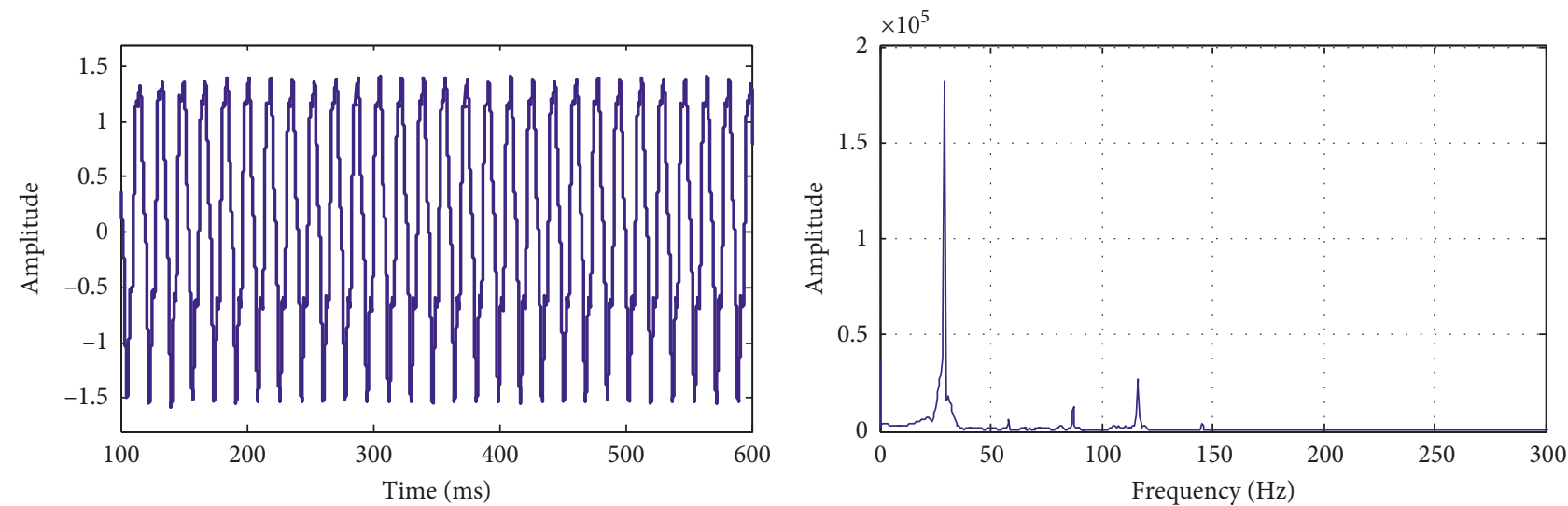

FIgURE 9: Vertical vibration amplitude signals and its frequency diagram on the disk.

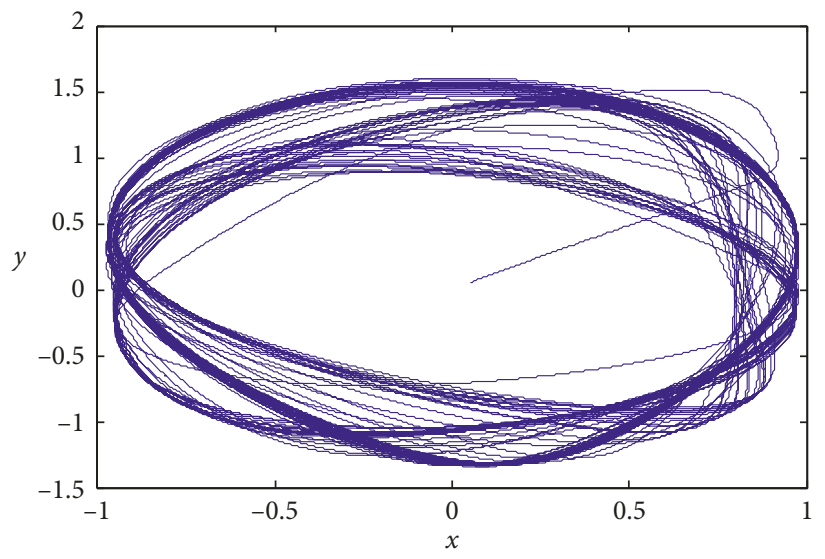

FIgURE 10: Orbits at the position of pedestal looseness (looseness clearance $=0.0002 \mathrm{~m}$ ).

As shown in Figure 15, the experimental setup that produced by SpectraQuest company consists of a rigid cylindrical shaft supported by two cylindrical journal bearings (an oil film journal bearing at the left end near the driving motor, and an oil film journal bearing in the position of pedestal looseness at the right end). The signal collector is B\&K Pulse. There are five accelerometers in the rig, which positions are supporters in the horizontal and vertical directions on the position of pedestal looseness, supporter in the horizontal and vertical directions at the left end, and on the position of fastening bolt. The experimental setup used in this paper is the same as in Reference [35]. The only difference in this paper is that no rubber gasket is used for the fastening bolt in the position of pedestal looseness, while a rubber gasket is used in Reference [35]. 

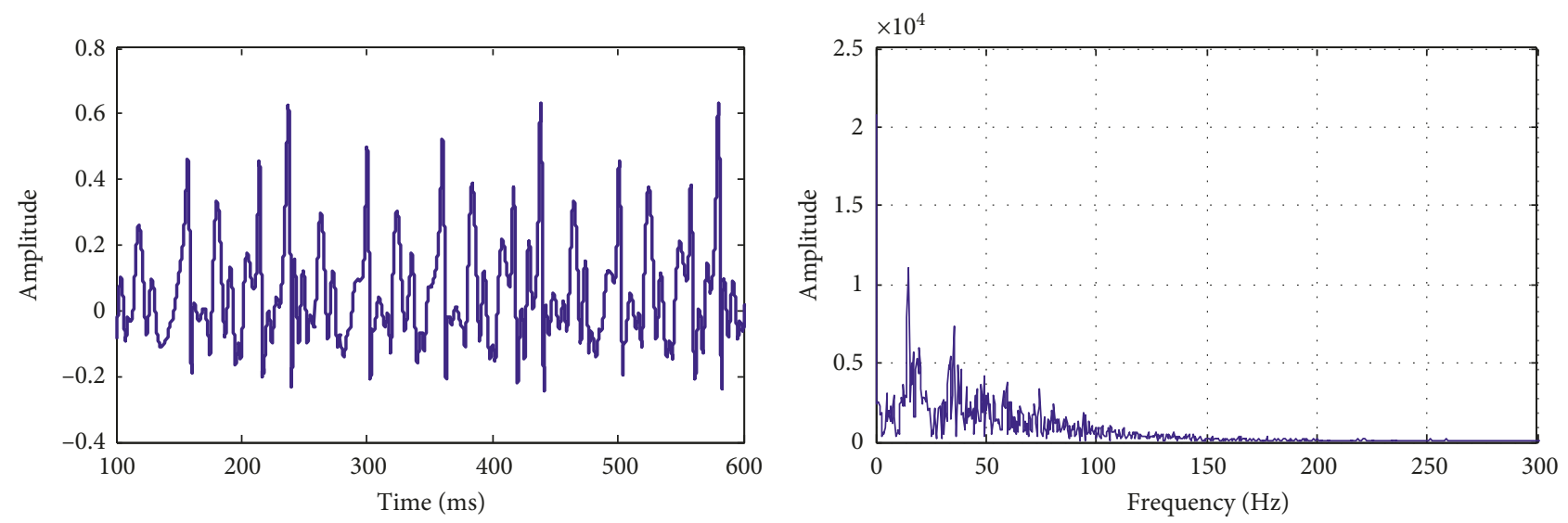

Figure 11: Vertical vibration amplitude signals and its frequency diagram on left bearing.
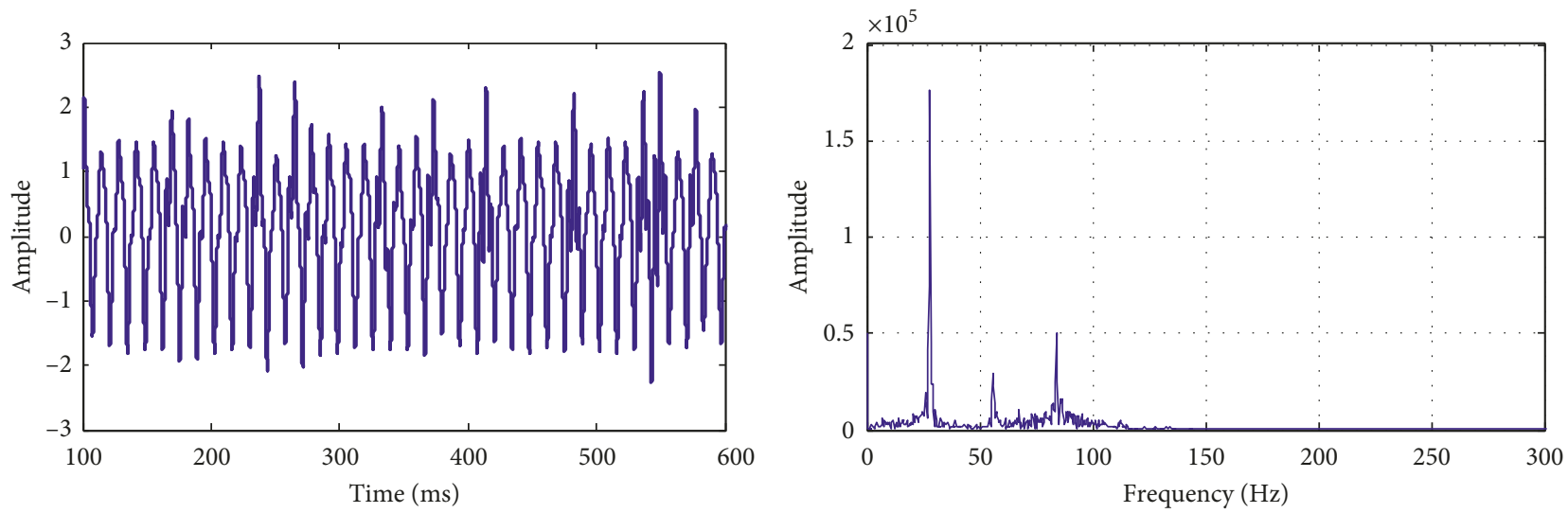

FIgURE 12: Vertical vibration amplitude signals and its frequency diagram on the disk.

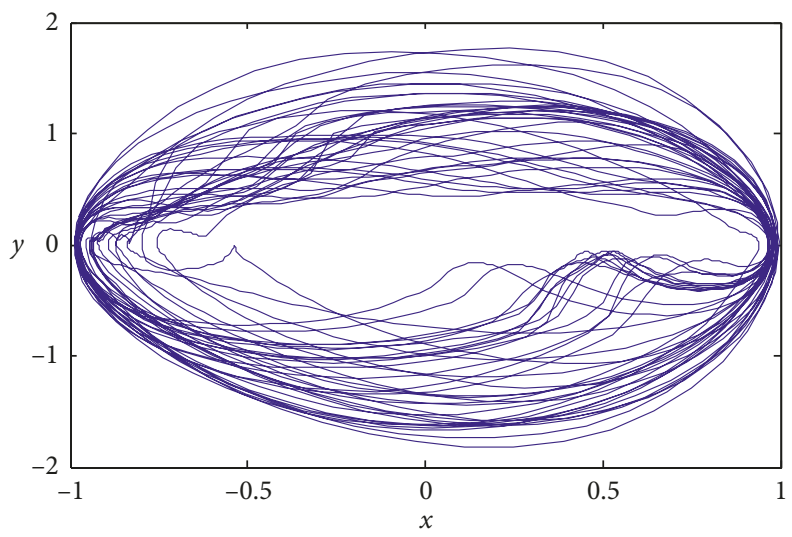

FIGURE 13: Orbits at the position of pedestal looseness (looseness clearance $=0.002 \mathrm{~m}$ ).

In the experiment mentioned above, the rotor speed is set to be $2100 \mathrm{rpm}$ and the sample frequency is $3.2 \mathrm{kHz}$. The pedestal looseness is simulated by adjusting the fastening bolt (8) according to the dial (9). The distance between threads is measured in advance, and the bolt can be adjusted according to the scale on the dial. The looseness clearances will change $1 \times 10^{-4}$ accordingly, when the M10 bolt is adjusted $36^{\circ}$. With the same conditions, the experiments for vibration signals acquisition are conducted into three stages. First, the vibration signals for the rotor system without pedestal looseness are collected as the basis of nonlinearity measure, and $d$ in equations (16) and (17) is computed numerically. Second, the experiments for the rotor system with single pedestal looseness are conducted to collect the vibration signals with different looseness clearances. Lastly, the experiments for rotor systems with pedestal looseness 


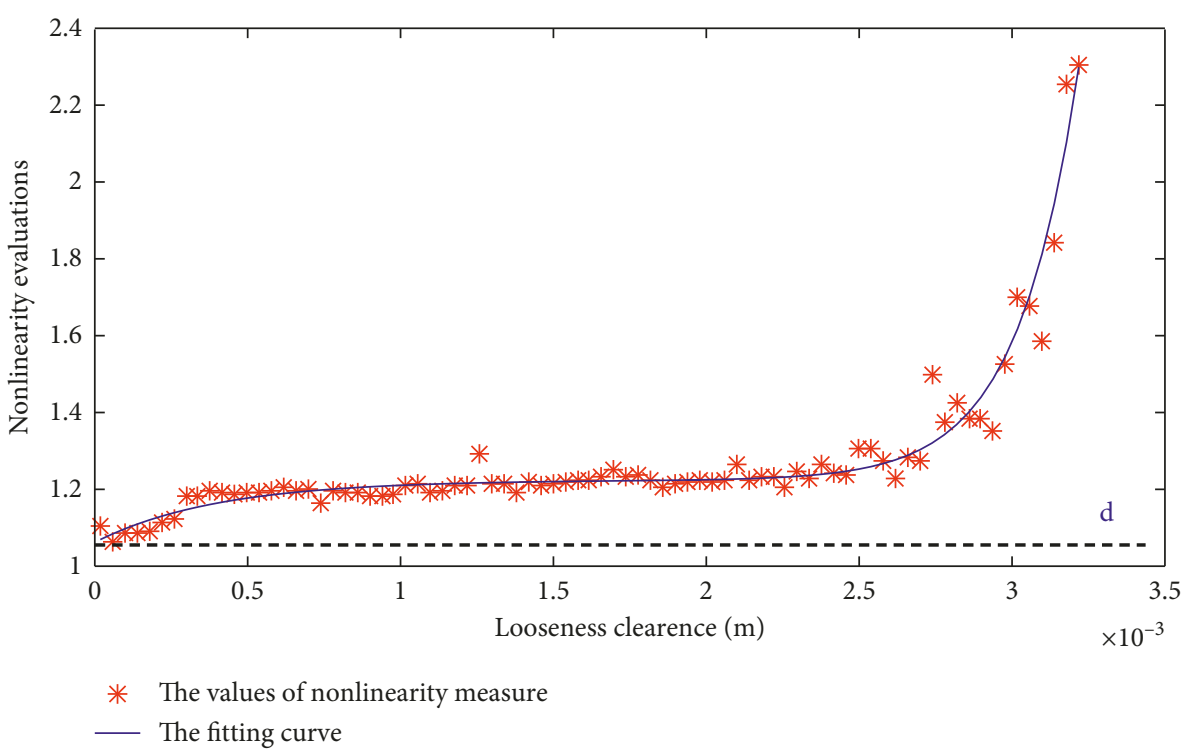

FIGURE 14: The relationship of results of nonlinearity measure and looseness clearances.

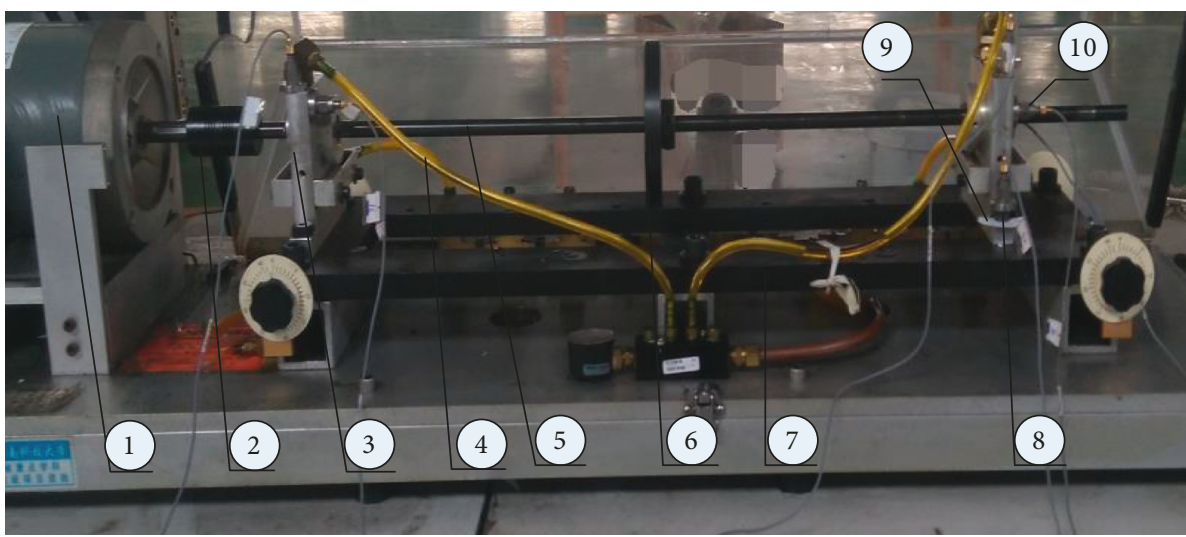

FigURE 15: Experiment setup.

coupled with rub-impact are implemented to collect the vibration acceleration signals with the same looseness clearances. The picture of the rubbing institution in the rotor system is shown in Figure 16.

Due to the restrictions of experiments, less number of looseness clearances can be used to implement the process of analysis and computations of nonlinearity quantification. The measurements for the vibration responses in the experiments are conducted with the same looseness clearances. Vibration signals and its amplitude spectrums of the supporter in the vertical direction are compared simultaneously. The vibration amplitudes are obtained by twice discrete Fourier transformations, while measured vibration acceleration signals are denoised by wavelet packets method. An orthogonal wavelet denoising is performed using the function wden in MATLAB for denoising. The discrete Meyer wavelet using function dmey is used as the basic wavelet in MATLAB. Five levels of decomposition are chosen in wavelet transform to have an accurate enough representation of the measured signals.
Because the results of nonlinearity evaluation should be obtained at every setting looseness clearance for two kinds of experiments, it needs a huge amount of computations. For simplification, only vibration signals and their amplitude spectrums for experiments of rotor systems without pedestal looseness and pedestal looseness coupled with rubbing can be exhibited here. In the first stage of the experiment, vibration signals and their amplitude spectrums of the supporter in the vertical direction for rotor system without pedestal looseness are given in Figure 17.

In the experiments for the rotor system with pedestal looseness coupled with rub-impact, Figures 18 and 19 are vibration signals and their amplitude spectrums of the supporter in the vertical direction on the position of pedestal looseness, where the looseness clearances are set to be $0.0002 \mathrm{~m}$ and $0.002 \mathrm{~m}$.

In order to compare this scenario to the scenario of single pedestal looseness, the same number of looseness clearances with equal intervals is used in order to calculate the dynamical behaviors of this rotor system, and the nonlinearity evaluation 


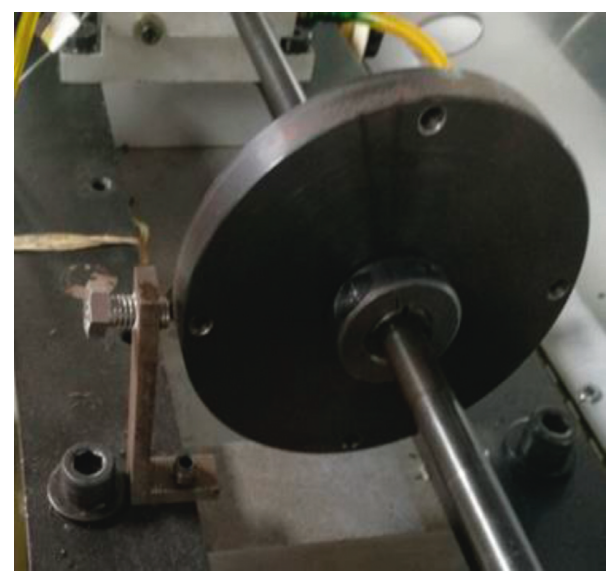

FIgURE 16: The schematic diagram of rubbing institutions.
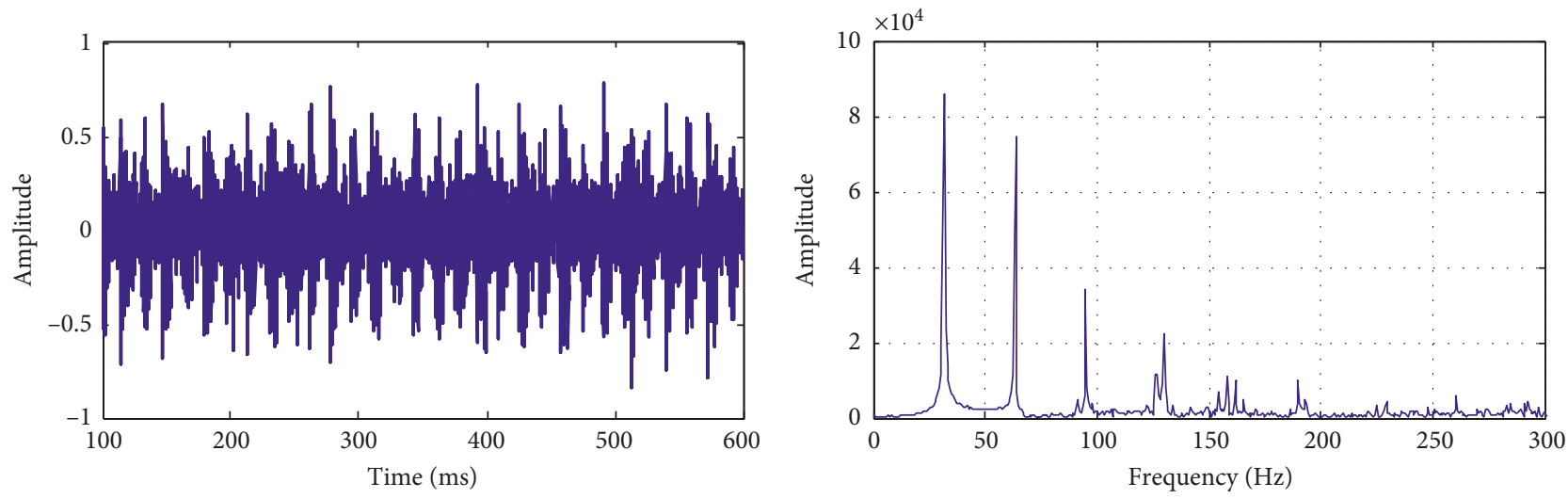

(a)
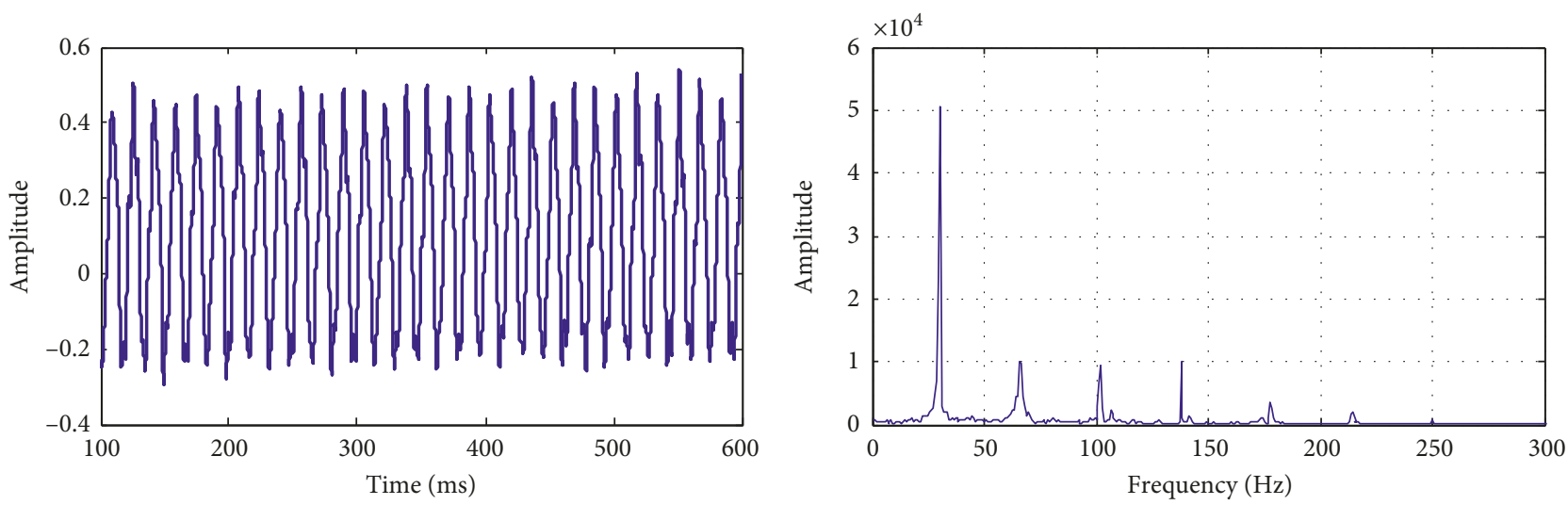

(b)

Figure 17: Vertical vibration amplitude signals and its frequency diagram on bearing without pedestal looseness. (a) Vibration amplitude signals and its frequency diagram. (b) Denosing vibration amplitude signals and its frequency diagram.

is then computed based on the vibration amplitudes. The values of nonlinearity measure are computed according to equations (16) and (17), and the inner product is calculated using the equation (19). Two curves are separately obtained using the nonlinear fitting method with exponential functions according to the values of the nonlinearity measure, which are shown in Figure 20. It can be found that the results of the nonlinearity evaluation are all equal or larger than $d$.
Each curve displays the trend for the results of the nonlinearity evaluation on different looseness clearances. When the looseness clearance is set to values greater than $0.0002 \mathrm{~m}$, the rub-impact is taken into consideration in the simulations, and the trend and the amplitude of the curve begins to change. Additionally, it is obvious that when small values are chosen for the looseness clearance, the results of the nonlinearity measure have a slow increasing trend. If 

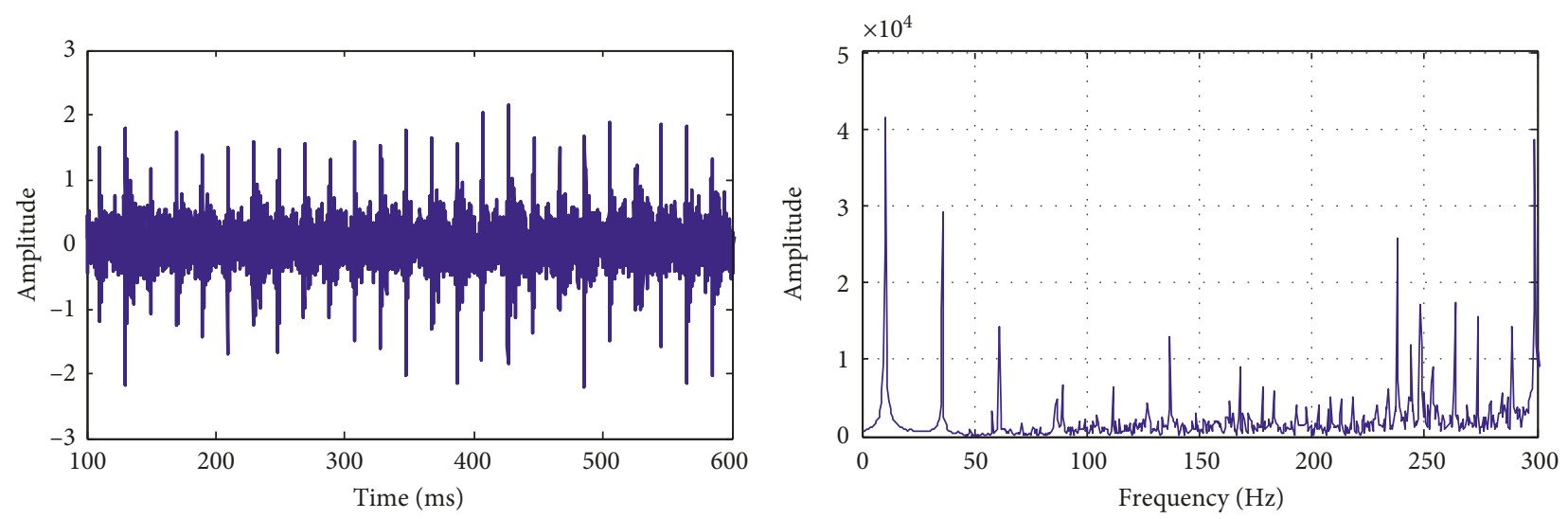

(a)
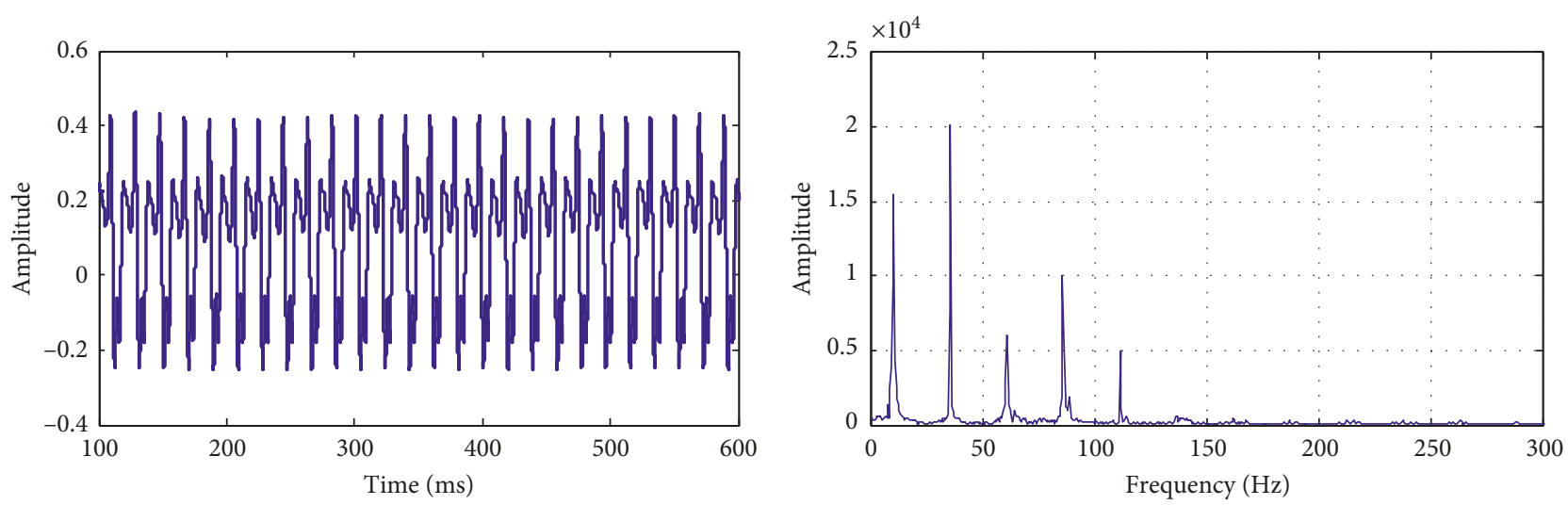

(b)

FIGURE 18: Vertical vibration amplitude signals and their frequency diagram on bearing with pedestal looseness coupled with rub-impact (looseness clearance $=0.0002 \mathrm{~m}$ ). (a) Vibration amplitude signals and its frequency diagram. (b) Denosing vibration amplitude signals and its frequency diagram.

values larger than the threshold are chosen for the looseness clearance, the nonlinearity evaluation of the rotor system with pedestal looseness coupled with rub-impact increases more dramatically than that of the rotor system with single pedestal looseness. It comes to the same conclusions with the numerical example.

On the other hand, the curve that denotes the trend of the nonlinearity evaluation for the rotor system with single pedestal looseness is close to a straight line, although it is also given by a fitting method with exponential functions. However, the curve that denotes the trend of the nonlinearity evaluation for the rotor system with pedestal looseness coupled with rub-impact displays more characteristics other than a straight line. As shown in Figure 20, the values of nonlinearity measure for the rotor system with pedestal looseness coupled with rub-impact is obviously lager than that with pure pedestal looseness on the same looseness clearances.

\section{Conclusions}

In this paper, a nonlinearity evaluation was proposed to identify the rub-impact in rotor systems with pedestal looseness. First, nonlinear mathematical models were established for bearing-rotor systems with single pedestal looseness and pedestal looseness coupled with rubimpact. The elastic force and rubbing force on the positions of pedestal looseness and rubbing points were taken into consideration. Secondly, the definition of nonlinearity evaluation is given, and a special case is applied to quantify the nonlinearity of dynamics for rotor systems. This evaluation is computed numerically based on the dynamical models on different looseness clearances. Finally, experiments are conducted to verify the effectiveness of the proposed method. The experiments for the rotor systems with pure pedestal looseness and pedestal looseness coupled with rub-impact are used to collect the vibration signals on different looseness clearances. Two different curves were obtained separately using a nonlinear fitting method with exponential functions, according to the values of the nonlinearity measure. It can be observed that if the rotor systems with pedestal looseness have a rub-impact between the stator and the rotor, the nonlinearity degree will have a larger value than rotor systems with pure pedestal looseness. This will provide a new idea to identify the rub-impact in rotor systems with pedestal looseness. 

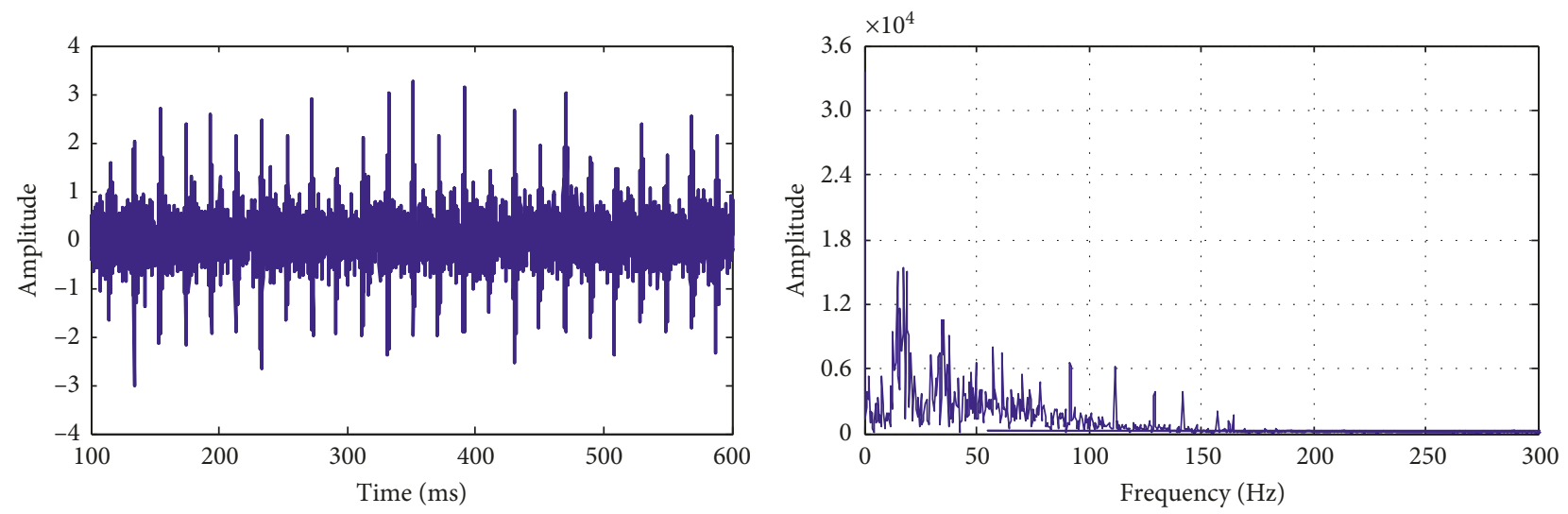

(a)
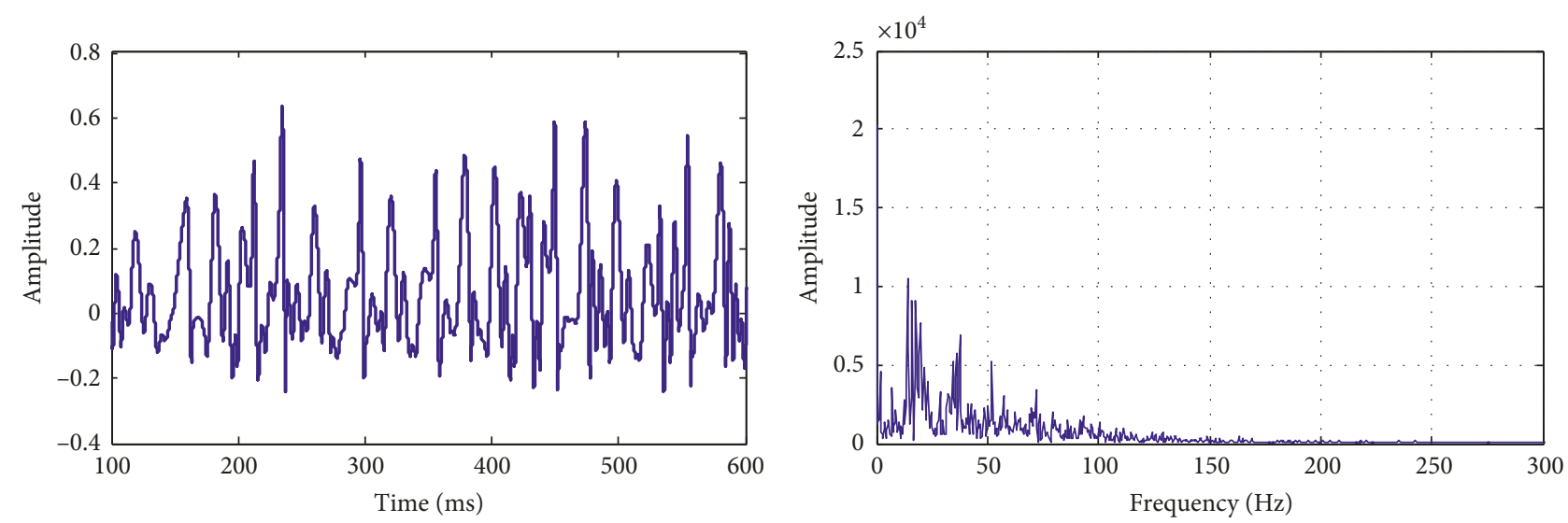

(b)

FIGURE 19: Vertical vibration amplitude signals and their frequency diagram on bearing with pedestal looseness coupled with rub-impact (looseness clearance $=0.002 \mathrm{~m}$ ). (a) Vibration amplitude signals and its frequency diagram. (b) Denosing vibration amplitude signals and its frequency diagram.

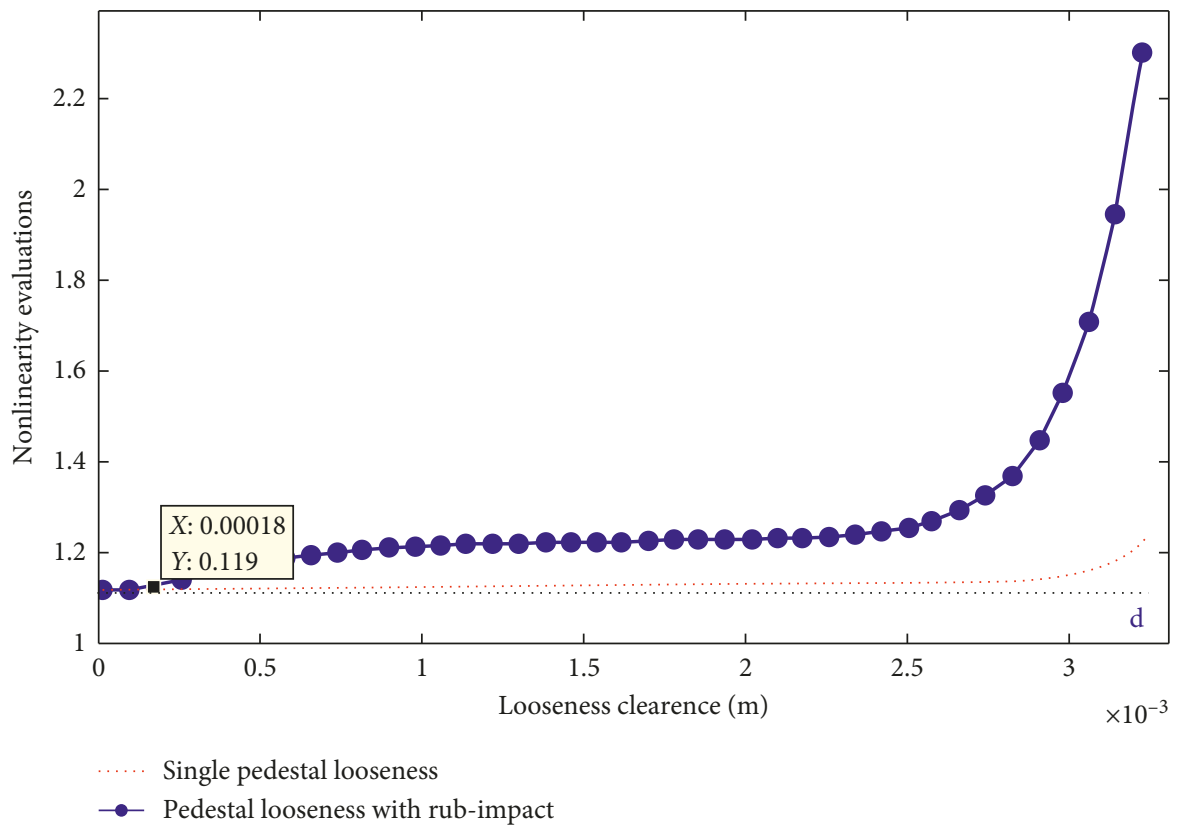

FIgURE 20: Comparisons for nonlinearity evaluations of pedestal looseness. 


\section{Appendix}

\section{A. The Procedure for Taylor Expansions of Nonlinear Terms}

Considering that the amplitudes of the vibrations or the velocity will have small perturbations on oil films, linear approximations for the oil film force components $F_{x}, F_{y}$ will have a good accuracy using the following equations:

$$
\left\{\begin{aligned}
F_{x} \approx & F_{x_{0}}+\left.\frac{\partial F_{x}}{\partial x}\right|_{\left(x_{0}, y_{0}\right)} \Delta x+\left.\frac{\partial F_{x}}{\partial y}\right|_{\left(x_{0}, y_{0}\right)} \Delta y \\
& +\left.\frac{\partial F_{x}}{\partial \dot{x}}\right|_{\left(x_{0}, y_{0}\right)} \Delta \dot{x}+\left.\frac{\partial F_{x}}{\partial \dot{y}}\right|_{\left(x_{0}, y_{0}\right)} \Delta \dot{y}, \\
F_{y} \approx & F_{y_{0}}+\left.\frac{\partial F_{y}}{\partial x}\right|_{\left(x_{0}, y_{0}\right)} \Delta x+\left.\frac{\partial F_{y}}{\partial y}\right|_{\left(x_{0}, y_{0}\right)} \Delta y \\
& +\left.\frac{\partial F_{y}}{\partial \dot{x}}\right|_{\left(x_{0}, y_{0}\right)} \Delta \dot{x}+\left.\frac{\partial F_{y}}{\partial \dot{y}}\right|_{\left(x_{0}, y_{0}\right)} \Delta \dot{y},
\end{aligned}\right.
$$

where $F_{x_{0}}, F_{y_{0}}$ are the oil film force components on the static equilibrium position, $\Delta x, \Delta y$ are the small displacement relative to the equilibrium position $\left(x_{0}, y_{0}\right)$ in the horizontal and vertical directions. For convenience, the following expressions are used to calculate the approximate oil film force components:

$$
\begin{aligned}
\left\{\begin{array}{l}
\widetilde{F}_{x} \\
\widetilde{F}_{y}
\end{array}\right\}= & {\left[\begin{array}{ll}
h_{x x} & h_{x y} \\
h_{y x} & h_{y y}
\end{array}\right]\left\{\begin{array}{l}
\Delta x \\
\Delta y
\end{array}\right\}+\left[\begin{array}{ll}
d_{x x} & d_{x y} \\
d_{y x} & d_{y y}
\end{array}\right]\left\{\begin{array}{l}
\Delta \dot{x} \\
\Delta \dot{y}
\end{array}\right\} } \\
& +\left\{\begin{array}{l}
F_{x_{0}} \\
F_{y_{0}}
\end{array}\right\},
\end{aligned}
$$

where

$$
\left\{\begin{array}{l}
h_{x x}=\left.\frac{\partial F_{x}}{\partial x}\right|_{\left(x_{0}, y_{0}\right)}, \\
h_{x y}=\left.\frac{\partial F_{x}}{\partial y}\right|_{\left(x_{0}, y_{0}\right)}, \\
h_{y x}=\left.\frac{\partial F_{y}}{\partial x}\right|_{\left(x_{0}, y_{0}\right)}, \\
h_{y y}=\left.\frac{\partial F_{y}}{\partial y}\right|_{\left(x_{0}, y_{0}\right)}, \\
d_{x x}=\left.\frac{\partial F_{x}}{\partial \dot{x}}\right|_{\left(x_{0}, y_{0}\right)}, \\
d_{x y}=\left.\frac{\partial F_{x}}{\partial \dot{y}}\right|_{\left(x_{0}, y_{0}\right)}, \\
d_{y x}=\left.\frac{\partial F_{y}}{\partial \dot{x}}\right|_{\left(x_{0}, y_{0}\right)}, \\
d_{y y}=\left.\frac{\partial F_{y}}{\partial \dot{y}}\right|_{\left(x_{0}, y_{0}\right)} .
\end{array}\right.
$$

$h_{x x}, h_{x y}, h_{y x}, h_{y y}$ are the stiffness coefficients caused by the change of unit displacement on the oil film, while $d_{x x}, d_{x y}, d_{y x}, d_{y y}$ are the damping coefficients caused by the change of unity velocity.

\section{B. The Values of Simulation Parameters}

The parameters used in the simulations are given in Tables 1-3 [35].

\section{Data Availability}

The data and the MATLAB programs used to support the findings of this study are available from the corresponding author upon request.

\section{Conflicts of Interest}

The authors declare that they have no conflicts of interest.

\section{Acknowledgments}

This project is supported by National Natural Science Foundation of China (grant nos. 51775182, 51775181, and 51305133), Natural Science Foundation of Hunan province in China (grant nos. 2018JJ3170 and 2016JJ4033), and Outstanding Youth Fund of the Education Department of Hunan Province (grant no. 16B093) are also gratefully acknowledged.

\section{References}

[1] H. Ma, T. Yu, Q. K. Han, Y. M. Zhang, B. C. Wen, and X. L. Chen, "Time-frequency features of two types of coupled rub-impact faults in rotor systems," Journal of Sound and Vibration, vol. 321, no. 3-5, pp. 1109-1128, 2009.

[2] A. Muszynska, "Rotor-to-stationary element rub-related vibration phenomena in rotating machinery-literature survey," The Shock and Vibration Digest, vol. 21, no. 3, pp. 3-11, 1989.

[3] L. Xiang, A. J. Hu, L. L. Hou, Y. P. Xiong, and J. T. Xing, "Nonlinear coupled dynamics of an asymmetric double-disc rotor-bearing system under rub-impact and oil-film forces," Applied Mathematical Modelling, vol. 40, no. 7-8, pp. 45054523, 2016.

[4] C. Wang, D. Y. Zhang, Y. H. Ma, Z. C. Liang, and J. Hong, "Theoretical and experimental investigation on the sudden unbalance and rub-impact in rotor system caused by blade off," Mechanical Systems and Signal Processing, vol. 76-77, pp. 111-135, 2016.

[5] H. M. Khanlo, M. Ghayour, and S. Ziaei-Rad, "Chaotic vibration analysis of rotating, flexible, continuous shaft-disk system with a rub-impact between the disk and the stator," Communications in Nonlinear Science and Numerical Simulation, vol. 16, no. 1, pp. 566-582, 2011.

[6] F. Chu and Z. Zhang, "Bifurcation and chaos in a rub-impact Jeffcott rotor system," Journal of Sound and Vibration, vol. 210, no. 1, pp. 1-18, 1998.

[7] I. Abu-Mahfouz and A. Banerjee, "On the investigation of nonlinear dynamics of a rotor with rub-impact using numerical analysis and evolutionary algorithms," Procedia Computer Science, vol. 20, pp. 140-147, 2013. 
[8] S. M. Lee and Y. S. Choi, "Fault diagnosis of partial rub and looseness in rotating machinery using Hilbert-Huang transform," Journal of Mechanical Science and Technology, vol. 22, no. 11, pp. 2151-2162, 2008.

[9] Z. Peng, Y. He, Q. Lu, and F. Chu, "Feature extraction of the rub-impact rotor system by means of wavelet analysis," Journal of Sound and Vibration, vol. 259, no. 4, pp. 1000-1010, 2003.

[10] N. Q. Hu, M. Chen, and X. S. Wen, "The application of stochastic resonance theory for early detecting rub-impact fault of rotor system," Mechanical Systems and Signal Processing, vol. 17, no. 4, pp. 883-895, 2003.

[11] Y. G. Lei, Z. J. He, and Y. Y. Zi, "Application of the EEMD method to rotor fault diagnosis of rotating machinery," Mechanical Systems and Signal Processing, vol. 23, no. 4, pp. 1327-1338, 2009.

[12] T. H. Patel and A. K. Darpe, "Study of coast-up vibration response for rub detection," Mechanism and Machine Theory, vol. 44, no. 8, pp. 1570-1579, 2009.

[13] Q. K. Han, H. L. Yao, and B. C. Wen, "A model-based identification approach for local fault of rotating machinery," Advances in Vibration Engineering, vol. 7, no. 4, pp. 365-376, 2008.

[14] P. Pennacchi and A. Vania, "Analysis of rotor-to-stator rub in a large steam turbo generator," International Journal of Rotating Machinery, vol. 2007, Article ID 90631, 8 pages, 2007.

[15] N. Bachschmid, P. Pennacchi, and A. Vania, "Identification of multiple faults in rotor systems," Journal of Sound and Vibration, vol. 254, no. 2, pp. 327-366, 2002.

[16] F. Chu and W. Lu, "Determination of the rubbing location in a multi-disk rotor system by means of dynamic stiffness identification," Journal of Sound and Vibration, vol. 248, no. 2, pp. 235-246, 2001.

[17] Y. Yang, J. S. Cheng, and K. Zhang, "An ensemble local means decomposition method and its application to local rub-impact fault diagnosis of the rotor systems," Measurement, vol. 45, no. 3, pp. 561-570, 2012.

[18] Y. X. Wang, R. Markert, J. W. Xiang, and W. G. Zheng, "Research on variational mode decomposition and its application in detecting rub-impact fault of the rotor system," Mechanical Systems and Signal Processing, vol. 60-61, pp. 243-251, 2016.

[19] H. L. Yao, Q. K. Han, L. X. Li, and B. C. Wen, "Detection of rubbing location in rotor system by super-harmonic responses," Journal of Mechanical Science and Technology, vol. 26, no. 8, pp. 2341-2437, 2012.

[20] J. D. Jeng, L. Hsu, C. W. Hun, and C. Y. Chou, "Identification for bifurcation and responses of rub-impacting rotor system," Procedia Engineering, vol. 79, pp. 369-377, 2014.

[21] L. L. Cui, J. F. Huang, and F. B. Zhang, "Quantitative and localization diagnosis of a defective ball bearing based on vertical-horizontal synchronization signal analysis," IEEE Transactions on Industrial Electronics, vol. 64, no. 11, pp. 8695-8705, 2017.

[22] L. L. Cui, N. Wu, C. Q. Ma, and H. Q. Wang, "Quantitative fault analysis of roller bearings based on a novel matching pursuit method with a new step-impulse dictionary," $\mathrm{Me}$ chanical Systems and Signal Processing, vol. 68-69, pp. 34-43, 2016.

[23] P. Goldman and A. Muszynska, "Analytical and experimental simulation of loose pedestal dynamic effects on a rotating machine vibrational response," Rotating Machinery and Vehicle Dynamics, American Society of Mechanical Engineers, vol. 35, pp. 11-17, 1991.
[24] Z. Ji and J. W. Zu, "Method of multiple scales for vibration analysis of rotor-shaft systems with nonlinear bearing pedestal model," Journal of Sound and Vibration, vol. 218, no. 2, pp. 293-305, 1998.

[25] X. L. An, D. Q. Jiang, S. H. Li, and M. H. Zhao, "Application of the ensemble empirical mode decomposition and Hilbert transform to pedestal looseness study of direct-drive wind turbine," Energy, vol. 36, no. 9, pp. 5508-5520, 2011.

[26] Y. S. Choi and S. M. Park, "Diagnosis on the clearance of rotating machinery using correlation dimension," Transactions of the Korean Society for Noise and Vibration Engineering, vol. 15, no. 7, pp. 134-139, 2004.

[27] H. Ma, X. Y. Zhao, and Y. N. Teng, "Analysis of dynamic characteristics for a rotor system with pedestal looseness," Shock and Vibration, vol. 18, no. 1-2, pp. 13-27, 2011.

[28] F. Chu and Y. Tang, "Stability and Nonlinear responses of a rotor-bearing system with pedestal looseness," Journal of Sound and Vibration, vol. 241, no. 5, pp. 879-893, 2001.

[29] F. Chu and W. X. Lu, "Experimental observation of nonlinear vibrations in a rub-impact rotor system," Journal of Sound and Vibration, vol. 283, no. 3-5, pp. 621-643, 2005.

[30] H. Ma, X. Y. Tai, B. Wang, and B. C. Wen, "Dynamic characteristic analysis of a rotor system with pedestal looseness coupled rub-impact fault," Journal of Mechanical Engineering, vol. 48, no. 19, pp. 80-86, 2012, in Chinese.

[31] T. Schweickhardt and F. Allgower, "Chapter A3: quantitative nonlinearity assessment-an introduction to nonlinearity measures," Computer Aided Chemical Engineering, vol. 17, pp. 76-95, 2004.

[32] A. Helbig, W. Marquardt, and F. AllgoÈwer, "Nonlinearity measures: definition, computation and applications," Journal of Process Control, vol. 10, no. 2-3, pp. 113-123, 2000.

[33] C. Chen and H. T. Yau, "Chaos in the imbalance response of a flexible rotor supported by oil film bearings with nonlinear suspension," Nonlinear Dynamics, vol. 16, pp. 71-98, 1998.

[34] Z. Liu, Y. Cui, J. Ye, and Y. Wang, "Research on vibration characteristics of gear system with nonlinear oil film force and mesh force," Proceedings of the CSEE, vol. 29, no. 23, pp. 84-91, 2009, in Chinese.

[35] M. Jiang, J. G. Wu, X. S. Peng, and X. J. Li, "Nonlinearity measure based assessment method for pedestal looseness of bearing-rotor systems," Journal of Sound and Vibration, vol. 411, pp. 232-246, 2017.

[36] M. Jiang, J. G. Wu, and S. Q. Liu, "The influence of slowly varying mass on severity of dynamics nonlinearity of bearingrotor systems with pedestal looseness," Shock and Vibration, vol. 2018, Article ID 3795848, 11 pages, 2018. 


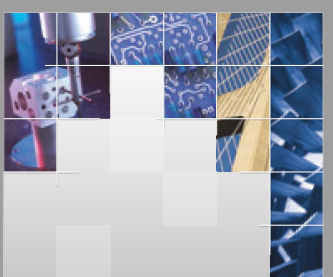

\section{Enfincering}
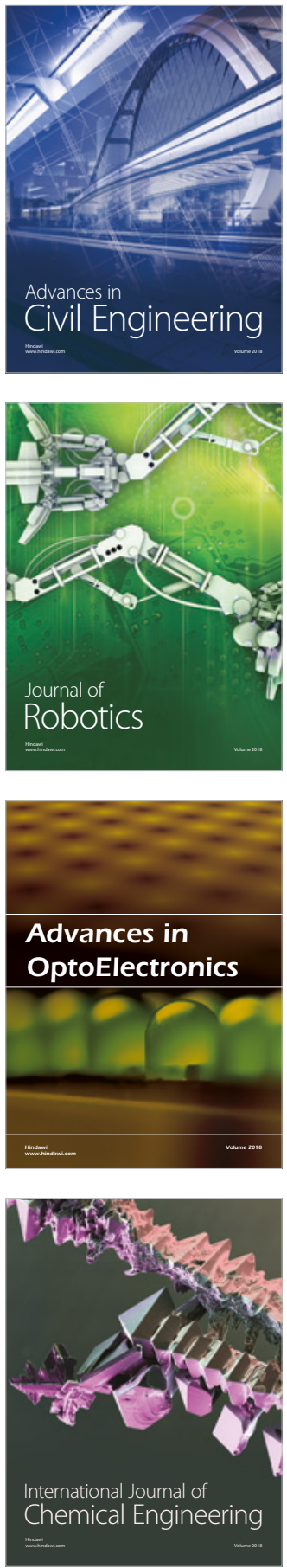

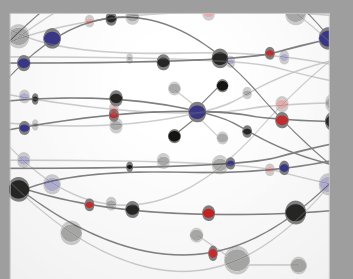

\section{Rotating \\ Machinery}

The Scientific World Journal

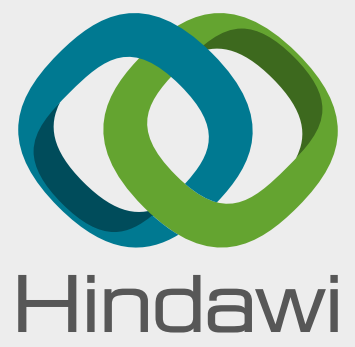

Submit your manuscripts at

www.hindawi.com
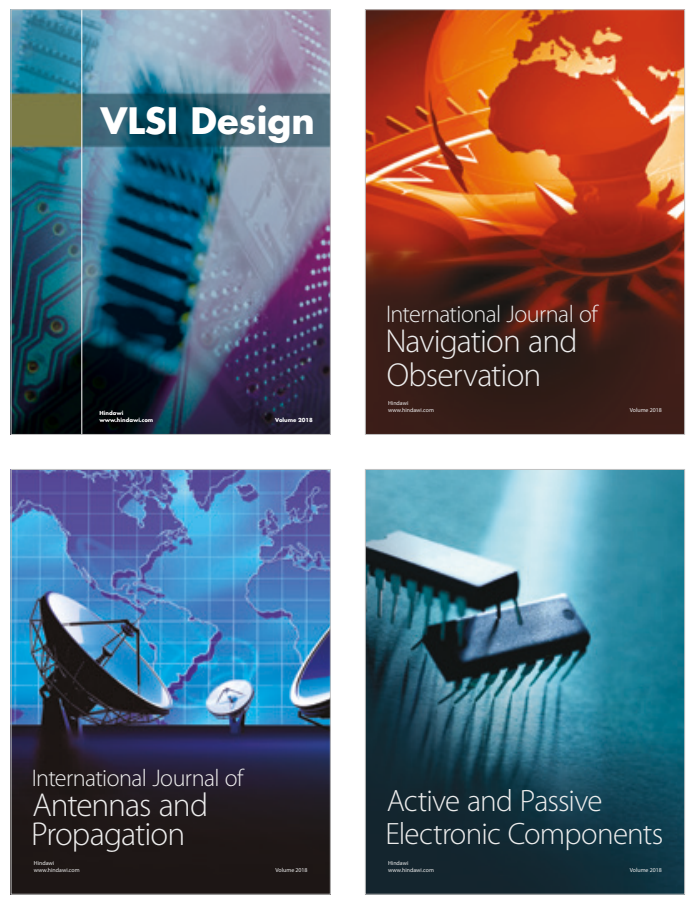
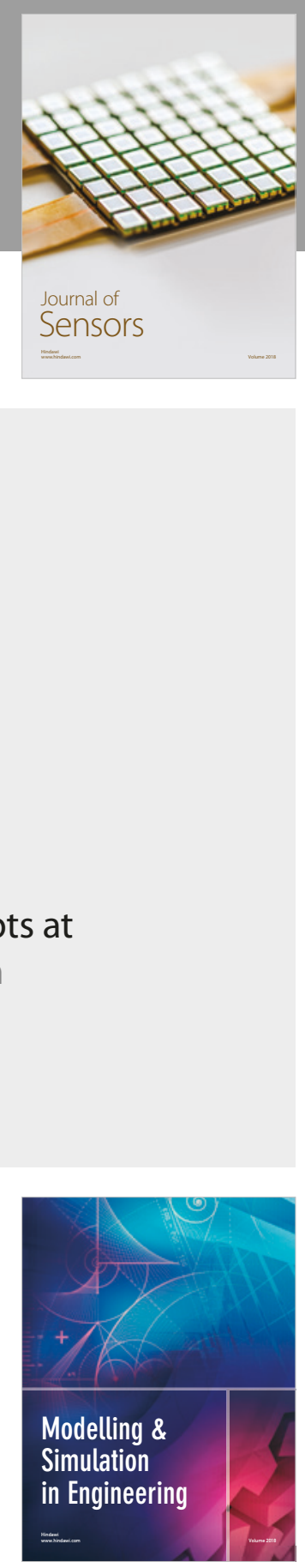

\section{Advances \\ Multimedia}
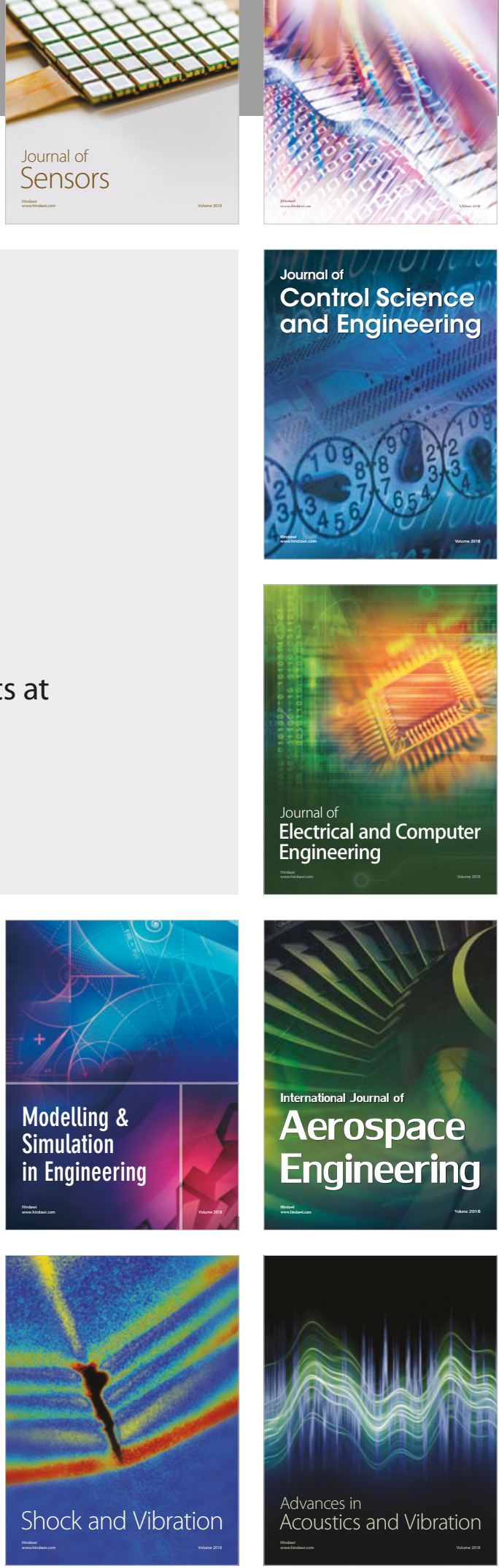